\title{
DEGRADATION OF CEMENTITIOUS MATERIALS ASSOCIATED WITH SALTSTONE DISPOSAL UNITS
}

\author{
G. P. Flach
}

F. G. Smith III

MARCH 2013

Savannah River National Laboratory

Savannah River Nuclear Solutions

Savannah River Site

Aiken, SC 29808

Prepared for the U.S. Department of Energy Under

Contract Number DE-AC09-08SR22470

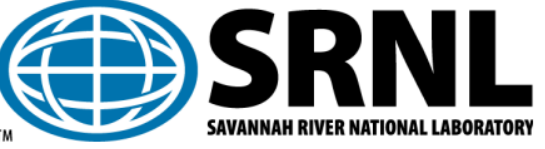




\section{DISCLAIMER}

This work was prepared under an agreement with and funded by the U.S. Government. Neither the U. S. Government or its employees, nor any of its contractors, subcontractors or their employees, makes any express or implied:

1. warranty or assumes any legal liability for the accuracy, completeness, or for the use or results of such use of any information, product, or process disclosed; or

2. representation that such use or results of such use would not infringe privately owned rights; or

3. endorsement or recommendation of any specifically identified commercial product, process, or service.

Any views and opinions of authors expressed in this work do not necessarily state or reflect those of the United States Government, or its contractors, or subcontractors.

Printed in the United States of America

Prepared for

U.S. Department of Energy 
Key Words:

Performance Assessment

Sulfate Attack

Carbonation

Decalcification

Retention:

Permanent

\title{
DEGRADATION OF CEMENTITIOUS MATERIALS ASSOCIATED WITH SALTSTONE DISPOSAL UNITS
}

\author{
G. P. Flach
}

F. G. Smith III

MARCH 2013

Savannah River National Laboratory

Savannah River Nuclear Solutions

Savannah River Site

Aiken, SC 29808 


\section{REVIEWS AND APPROVALS}


SRNL-STI-2013-00118, REVISION 0

\section{EXECUTIVE SUMMARY}

The Saltstone facilities at the DOE Savannah River Site (SRS) stabilize and dispose of low-level radioactive salt solution originating from liquid waste storage tanks at the site. The Saltstone Production Facility (SPF) receives treated salt solution and mixes the aqueous waste with dry cement, blast furnace slag, and fly ash to form a grout slurry which is mechanically pumped into concrete disposal cells that compose the Saltstone Disposal Facility (SDF). The solidified grout is termed "saltstone”.

Cementitious materials play a prominent role in the design and long-term performance of the SDF. The saltstone grout exhibits low permeability and diffusivity, and thus represents a physical barrier to waste release. The waste form is also reducing, which creates a chemical barrier to waste release for certain key radionuclides, notably Tc-99. Similarly, the concrete shell of an SDF disposal unit (SDU) represents an additional physical and chemical barrier to radionuclide release to the environment. Together the waste form and the SDU compose a robust containment structure at the time of facility closure. However, the physical and chemical state of cementitious materials will evolve over time through a variety of phenomena, leading to degraded barrier performance over Performance Assessment (PA) timescales of thousands to tens of thousands of years. Previous studies of cementitious material degradation in the context of low-level waste disposal have identified sulfate attack, carbonation influenced steel corrosion, and decalcification (primary constituent leaching) as the primary chemical degradation phenomena of most relevance to SRS exposure conditions.

In this study, degradation time scales for each of these three degradation phenomena are estimated for saltstone and concrete associated with each SDU type under conservative, nominal, and best estimate assumptions. The nominal value (NV) is an intermediate result that is more probable than the conservative estimate (CE) and more defensible than the best estimate (BE). The combined effects of multiple phenomena are then considered to determine the most limiting degradation time scale for each cementitious material. Degradation times are estimated using a combination of analytic solutions from literature and numerical simulation codes provided through the DOE Cementitious Barriers Partnership (CBP) Software Toolbox (http://cementbarriers.org).

For the SDU 2 design, the roof, wall, and floor components are projected to become fully degraded under Nominal conditions at 3866, 923, and 1413 years, respectively. For SDU 4 the roof and floor are estimated to be fully degraded under Nominal conditions after 1137 and 1407 years, respectively; the wall is assumed to be fully degraded at time zero in the most recent PA simulations. Degradation of these concrete barriers generally occurs from combined sulfate attack and corrosion of embedded steel following carbonation. Saltstone is projected to degrade very slowly by decalcification, with complete degradation occurring in excess of 200,000 years for any SDU type. Complete results are provided in Tables 5-1 through 5-3. 


\section{TABLE OF CONTENTS}

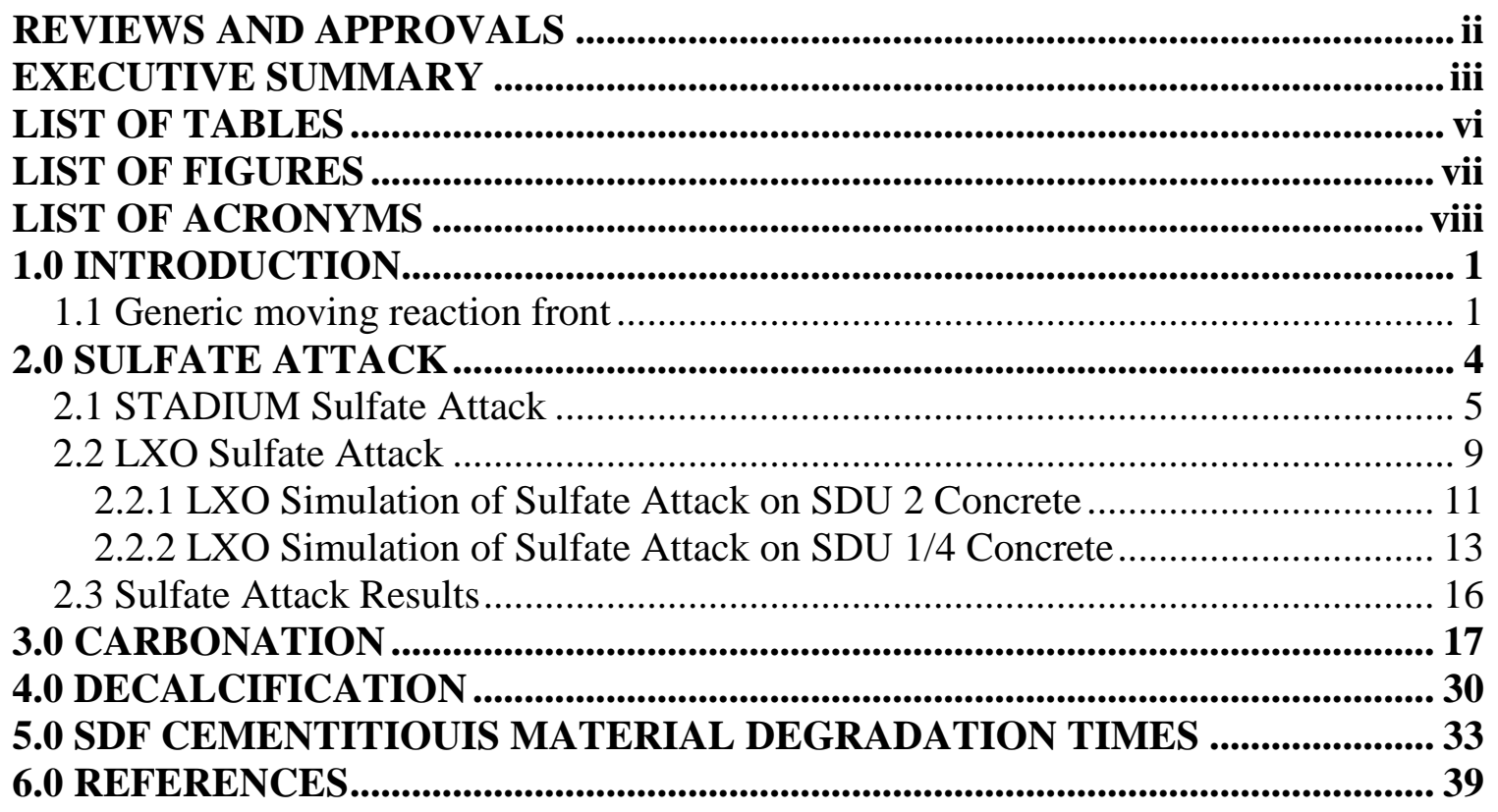

\section{LIST OF TABLES}

Table 2-1. Results from STADIUM concrete degradation simulations........................ 7

Table 2-2. SDU 2 LXO sulfate attack calculations for $20 \mathrm{~cm}$ of concrete................... 11

Table 2-3. SDU 2 LXO sulfate attack calculations for $30 \mathrm{~cm}$ of concrete................... 11

Table 2-4. SDU 1/4 LXO sulfate attack calculations for $45 \mathrm{~cm}$ of concrete. .............. 14

Table 2-5. SDU 1/4 LXO sulfate attack calculations for $60 \mathrm{~cm}$ of concrete. .............. 14

Table 2-6. Sulfate attack rates for SDU 2 and SDU 1/4 concrete............................. 17

Table 3-1. Input data and rate constants for carbonation calculations....................... 19

Table 3-2. Estimated calcium content in SDU 1 and 4 roof concrete relative to SDU

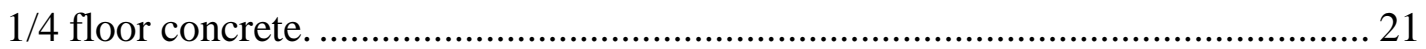

Table 3-3. Saltstone and concrete saturation for selected capillary suctions. .............. 24

Table 3-4. Pore fluid composition for SDU 2 concrete (SIMCO 2012, Table 11)..... 25

Table 3-5. Pore fluid composition for SDU 1/4 concrete (SIMCO 2012, Table 11)... 25

Table 3-6. Pore fluid composition for saltstone (SIMCO 2010, Table 8)................... 25

Table 3-7. Relative humidity and capillary suction corresponding to a total suction of

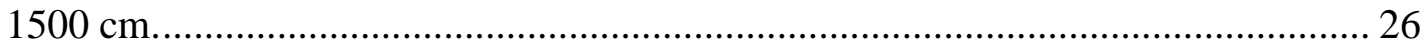

Table 4-1. Input data and rate constants for diffusion-limited decalcification. ........... 32

Table 4-2. Measured hydraulic conductivity from SRNL-STI-2012-00558 (Reigel et

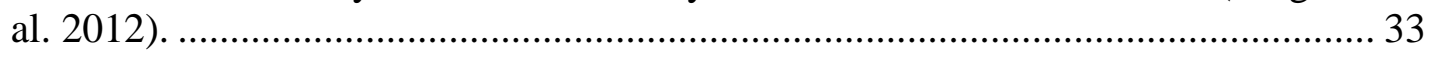

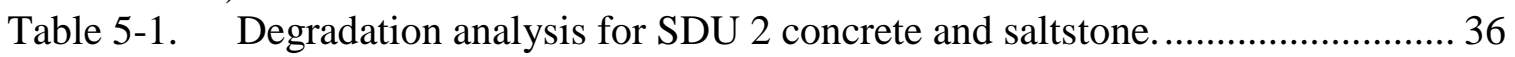

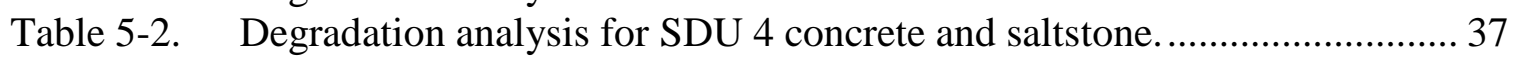

Table 5-3. Degradation analysis for SDU 1 concrete and saltstone........................... 38

Table 5-4. Degradation of HDPE and HDPE-GCL materials.................................. 39 


\section{LIST OF FIGURES}

Figure 1-1. Generic moving reaction front controlled by diffusion.

Figure 2-1. STADIUM prediction of sulfate attack on SDU 2 concrete at saltstone/concrete interface using default CBP Toolbox parameters.

Figure 2-2. STADIUM prediction of sulfate attack on SDU 2 concrete at 1000 and 5000 years.

Figure 2-3. STADIUM prediction of sulfate attack on SDU $1 / 4$ concrete at 1000 years. 8

Figure 2-4. Ettringite front penetration as a function of time for $30 \mathrm{~cm}$ of SDU 2 concrete with a fractional porosity of 0.6 .

Figure 2-5. Maximum ettringite front penetration as a function of time for $30 \mathrm{~cm}$ of SDU 2 concrete with a fractional porosity of 0.6 .

Figure 2-6. Ettringite front penetration as a function of concrete fractional porosity for $20 \mathrm{~cm}$ SDU 2 concrete.

Figure 2-7. Ettringite front penetration as a function of concrete fractional porosity for $30 \mathrm{~cm}$ SDU 2 concrete.

Figure 2-8. Predicted times for $100 \%$ SDU 2 concrete degradation as a function of fractional porosity.

Figure 2-9. Ettringite front penetration as a function of concrete fractional porosity for $45 \mathrm{~cm}$ SDU $1 / 4$ concrete.

Figure 2-10. Ettringite front penetration as a function of concrete fractional porosity for $60 \mathrm{~cm}$ SDU $1 / 4$ concrete.

Figure 2-11. Predicted time for $100 \%$ SDU $1 / 4$ concrete degradation as a function of fractional porosity.

Figure 3-1. Water retention curves for SDF concrete and saltstone.............................. 23

Figure 3-2. Carbonation simulation results as a function of soil-gas $\mathrm{CO}_{2}$ concentration for $90 \%$ concrete saturation from Brown et al (2012) (VCT = SDU 2 concrete, HPC = high performance concrete).............................................................................. 29

Figure 3-3. Square-root and linear penetration with respect to time.............................. 30 


\section{LIST OF ACRONYMS}

$\begin{array}{ll}\text { ACI } & \text { American Concrete Institute } \\ \text { BE } & \text { Best Estimate } \\ \text { CBP } & \text { Cementitious Barriers Partnership } \\ \text { CE } & \text { Conservative Estimate } \\ \text { CSH } & \text { Calcium-Silicate-Hydrate } \\ \text { CRESP } & \text { Consortium for Risk Evaluation with Stakeholder Participation } \\ \text { DOE } & \text { Department of Energy } \\ \text { NV } & \text { Nominal Value } \\ \text { PA } & \text { Performance Assessment } \\ \text { SDF } & \text { Salt Disposal Facility } \\ \text { SDU } & \text { Saltstone Disposal Unit } \\ \text { SPF } & \text { Salt Processing Facility } \\ \text { SRS } & \text { Savannah River Site } \\ \text { SRR } & \text { Savannah River Remediation } \\ \text { SRNL } & \text { Savannah River National Laboratory }\end{array}$




\subsection{INTRODUCTION}

The Saltstone facilities at the DOE Savannah River Site (SRS) stabilize and dispose of low-level radioactive salt solution originating from liquid waste storage tanks at the site. The Saltstone Production Facility (SPF) receives treated salt solution and mixes the aqueous waste with dry cement, blast furnace slag, and fly ash to form a grout slurry which is mechanically pumped into concrete Saltstone Disposal Units (SDUs) that compose the Saltstone Disposal Facility (SDF). The solidified grout is termed "saltstone". The Performance Assessment for the Saltstone Disposal Facility at the Savannah River Site (SRR 2009) and supporting documents provide further information about the general design and operation of the SDF.

Cementitious materials play a prominent role in the design and long-term performance of the SDF. Saltstone exhibits low permeability and diffusivity, and thus represents a physical barrier to waste release. The waste form is also reducing, which creates a chemical barrier to waste release for certain key radionuclides, notably Tc-99. Similarly, the concrete shell of an SDU represents an additional physical and chemical barrier to radionuclide release to the environment. Together the waste form and disposal cell compose a robust containment structure at the time of facility closure.

However, the physical and chemical state of cementitious materials will evolve over time through a variety of phenomena, leading to degraded barrier performance over Performance Assessment (PA) timescales of thousands to tens of thousands of years. Previous studies of cementitious material degradation in the context of low-level waste disposal have identified sulfate attack, carbonation influenced steel corrosion, and decalcification (primary constituent leaching) as the primary chemical degradation phenomena of most relevance to SRS exposure conditions (Walton et al. 1990, Langton 2007, 2010a, Samson et al. 2009).

In this study, degradation time scales for each of these three degradation phenomena are estimated for saltstone and the SDU concrete associated with each SDU type under conservative, nominal, and best estimate assumptions. The nominal value (NV) is an intermediate result that is more probable than the conservative estimate (CE) and more defensible than the best estimate (BE). The combined effects of multiple phenomena are then considered to determine the most limiting degradation time scale for each cementitious material. Degradation times are estimated using a combination of analytic solutions from literature and numerical simulation codes provided through the DOE Cementitious Barriers Partnership (CBP) Software Toolbox (http://cementbarriers.org).

\subsection{Generic moving reaction front}

The degradation mechanisms under consideration share the same basic functional form when the chemical reaction zone moves slowly as a sharp front across the porous medium and diffusion with constant diffusivity is the dominant transport mode for the fluid (gas or liquid) phase reactant, as shown in Figure 1-1. 


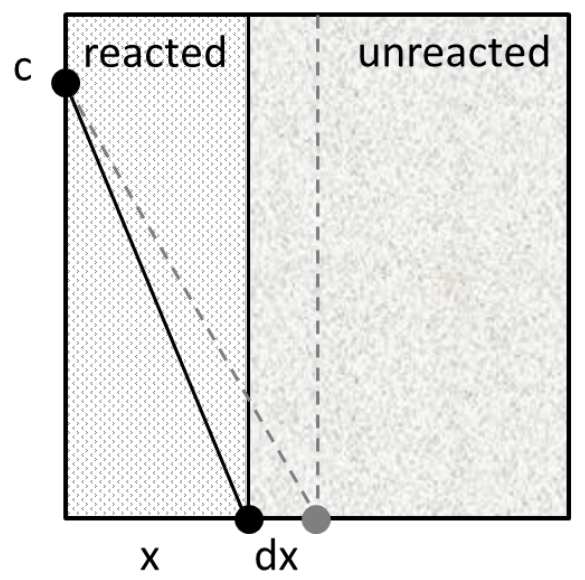

Figure 1-1. Generic moving reaction front controlled by diffusion.

The differential molar balance for this generic moving front system is

$$
\operatorname{Sn\tau } D_{m} \frac{c}{x} d t=R(1-n) \rho_{s} d x
$$

where

$$
\begin{aligned}
& S=\text { saturation of fluid phase delivering reactant to moving front } \\
& {\left[\mathrm{cm}^{3} \text { phase } / \mathrm{cm}^{3}\right. \text { void] }} \\
& n=\text { porosity }\left[\mathrm{cm}^{3} \text { void } / \mathrm{cm}^{3} \text { total }\right] \\
& \tau=\text { tortuosity, defined here as the ratio of effective to molecular diffusion } \\
& \text { coefficient }(<1)[-] \\
& D_{m}=\text { molecular diffusion coefficient for fluid phase }\left[\mathrm{cm}^{2} / \mathrm{yr}\right] \\
& x=\text { penetration depth }[\mathrm{cm}] \\
& t=\text { elapsed time [yr] } \\
& c=\text { concentration of fluid phase reactant }\left[\mathrm{mol} / \mathrm{cm}^{3} \text { phase }\right] \\
& R=\text { reaction capacity of solid [mol / g solid], i.e., moles of fluid phase reactant } \\
& \text { consumed per mass of solid } \\
& \rho_{s}=\text { solid / mineral density }\left[\mathrm{g} / \mathrm{cm}^{3} \text { solid }\right]
\end{aligned}
$$

Integration of Equation (1.1) yields the following analytic expression for penetration depth

$$
x=\left[\frac{2 \operatorname{Sn} \tau D_{m} c t}{(1-n) \rho_{s} R}\right]^{1 / 2}
$$


Inspection of Equation (1.2) indicates that movement of the reaction front is proportional or inversely proportional to the square root of all quantities except porosity. Equation (1.2) can be used to define the relative effect of a parameter change compared to a baseline result. For example, a modified exposure concentration $\left(c_{2}\right)$ produces an altered penetration depth $\left(x_{2}\right)$ given by

$$
x_{2}=\left[\frac{c_{2}}{c_{1}}\right]^{1 / 2} x_{1}
$$

where $c_{1}$ and $x_{1}$ are the baseline conditions.

The effective reaction capacity of a numerical reactive transport model can be derived using Equation (1.2) for a selected penetration depth $\left(x_{0}\right)$ and time $\left(t_{0}\right)$ as

$$
R=\frac{2 S n \tau D_{m} c t_{0}}{(1-n) \rho_{s} x_{0}^{2}}
$$

Equation (1.4) is useful for translating numerical simulation results into the equivalent analytic form given by Equation (1.2), assuming the numerical model exhibits the underlying behavior implied by Equation (1.2). Alternatively, Equation (1.2) can be written as

$$
x=A t^{1 / 2}
$$

where the rate constant $A$ is defined by

$$
A=\left[\frac{2 \operatorname{Sn} \tau D_{m} c}{(1-n) \rho_{s} R}\right]^{1 / 2}
$$

and empirically derived from a numerical simulation result $\left(t_{0}, x_{0}\right)$ as

$$
A=\frac{x_{0}}{t_{0}^{1 / 2}}
$$

The time $t_{0}$ associated with a certain penetration depth $x_{0}$ is

$$
t_{0}=\frac{x_{0}^{2}}{A^{2}}
$$

Equations (1.2) through (1.8) are generally applicable to all three degradation mechanisms being considered in this study (provided that the diffusion coefficient is fixed), although the particulars differ. In the case of sulfate attack, sulfate dissolved in the liquid phase diffuses into the porous medium, and reacts with the solid forming ettringite. In the case of carbonation, carbon dioxide in the gas phase diffuses in, reacts with the solid forming calcite, and the $\mathrm{pH}$ is lowered. In the case of decalcification, the 'reaction' is calcium in the solid dissolving into the liquid phase; the dissolved calcium then diffuses out of the porous medium. The report sections that follow address the specific analyses performed for sulfate attack, carbonation, and decalcification. 
SRNL-STI-2013-00118, REVISION 0

\subsection{SULFATE ATTACK}

Pore water in the saltstone waste form is expected to contain on the order of $0.1 \mathrm{M}$ sulfate. Over time, as sulfate ions migrate into the cement barrier surrounding the waste and react with calcium hydroxide (Portlandite) to form calcium sulfate (gypsum) according to the reaction:

$$
\mathrm{Ca}(\mathrm{OH})_{2}+\mathrm{SO}_{4}^{2-}+2 \mathrm{H}_{2} \mathrm{O} \rightarrow \mathrm{CaSO}_{4} \cdot 2 \mathrm{H}_{2} \mathrm{O}+2 \mathrm{OH}^{-}
$$

Calcium sulfate reacts with calcium/aluminum oxide minerals to form calcium aluminum sulfates such as ettringite according to the overall reaction:

$$
3 \mathrm{CaO} \bullet \mathrm{Al}_{2} \mathrm{O}_{3} \bullet 6 \mathrm{H}_{2} \mathrm{O}+3 \mathrm{CaSO}_{4}+20 \mathrm{H}_{2} \mathrm{O} \rightarrow 3 \mathrm{CaO} \bullet \mathrm{Al}_{2} \mathrm{O}_{3} \cdot 3 \mathrm{CaSO}_{4} \bullet 26 \mathrm{H}_{2} \mathrm{O}
$$

These reactions alter the mineral content of the concrete. Products of the sulfate reactions have a greater volume than the reactants. The resulting expansion of the solid phase leads to cracking which has a deleterious impact on structural integrity and the ability of the cementitious barrier to contain the radioactive waste. Sulfate attack has been identified as one of the primary mechanisms for the degradation of Saltstone concrete (SRR 2009, Samson et al. 2009, Sarkar, et al., 2010a).

The Cementitious Barriers Partnership (CBP) Project is a multi-disciplinary, multiinstitutional collaboration supported by the United States Department of Energy (US DOE) Office of Tank Waste Management with the objective of developing a set of tools to improve understanding and prediction of the long-term performance of cementitious barriers used in nuclear applications. The CBP is a partnership of federal, academic, private sector, and international expertise. In addition to the US DOE, the CBP partners are the Savannah River National Laboratory (SRNL), Consortium for Risk Evaluation with Stakeholder Participation (CRESP) at Vanderbilt University (VU), Energy Research Center of the Netherlands (ECN), and SIMCO Technologies, Inc. The Nuclear Regulatory Commission (NRC) is providing support under a Memorandum of Understanding. The National Institute of Standards and Technology (NIST) is providing research under an Interagency Agreement.

The CBP Project has released a Software Toolbox that includes two models that can be used to assess sulfate attack on SDUs (Brown, et al., 2013b). One model is a version of the STADIUM code developed by SIMCO (Samson, 2010) which models the transport of chemical ions and water through porous materials and reactions between the chemical and mineral species. The model solves a set of coupled differential equations describing one dimensional transport processes while simultaneously evaluating local diffusion coefficients and equilibrium chemical and mineral compositions in the materials. STADIUM can model systems with one (concrete), two (concrete and saltstone) or three (concrete, saltstone and soil) layers of materials. One limitation of STADIUM modeling is that structural changes and damage to the concrete have no direct impact on the diffusion and transport properties. 
The other model included in the CBP Toolbox is a sulfate attack module based on LeachXS/Orchestra (LXO) developed at the ECN and Vanderbilt University with CRESP funding (Sarkar et al. 2010a, b, 2011; Meeussen, et al., 2010). Similar to STADIUM, LXO calculates transport rates of species through porous media and chemical equilibria between local chemical and mineral phases. However, the LXO sulfate attack module also performs a damage calculation and modifies transport properties where damage is predicted. LXO models the material as a network of interconnected cells within which chemical equilibrium is maintained while transport of chemical species between cells occurs by diffusion and convection. The version of LXO released with the initial CBP Toolbox only allows modeling a single material.

\subsection{STADIUM Sulfate Attack}

Simulations of SDU 2 and SDU 1/4 concrete degradation were performed using the STADIUM code through the CBP Toolbox interface. For quality assurance, a preliminary run was made to confirm that the STADIUM model in the CBP Toolbox reproduced results for SDU 2 concrete as reported by Samson (2010) and again by Protiere et al. (2012). Using the data and parameters in the CBP Toolbox, the STADIUM model was run to simulate 1,000 years of concrete degradation for SDU 2 concrete. The concrete thickness was $20 \mathrm{~cm}$ (8 in) which is representative of the SDU 2 wall and roof thickness. Results from this trial calculation are plotted in Figure 2.1 which shows that, after 1,000 years of exposure, an ettringite mineral front has penetrated to a depth of approximately $2.5 \mathrm{~cm}$ from the saltstone interface (the concrete layer is from $120 \mathrm{~cm}$ to $140 \mathrm{~cm}$ in the plot). The shape of the ettringite front is consistent with that shown in the previous reports and the front depth is in agreement with the value reported at 1000 years in the cited publications. Using a simple linear extrapolation, this result would predict a concrete life of approximately 8,000 years.

However, in June 2010 SIMCO published a revised saltstone composition (SIMCO, 2010) which corrected an error in previous formulations and which produced a wasteform significantly more resistant to chemical attack. In March 2012, SIMCO also published a document (SIMCO, 2012) revising the SDU concrete compositions and properties based on better characterization of the constituent materials. The revised SDU 2 saltstone and revised concrete compositions were run using the STADIUM model with the CBP Toolbox. The simulations used a sulfate concentration in the pore fluid of $0.1 \mathrm{M}$ resulting from a mixing solution concentration of $0.05 \mathrm{M}$. As points of reference, a recent WAC (Waste Acceptance Criteria) sample from Tank 50 had a sulfate concentration of $0.05 \mathrm{M}$ (Bannochie 2011) and the sulfate concentration in feedwater to the SPF assumed in the Saltstone PA is $0.10 \mathrm{~mol} / \mathrm{L}$ (Dean 2009). Results of the STADIUM calculations are shown in Figure 2.2 for simulations of 1,000 and 5,000 years. The revised compositions yielded significantly reduced ettringite penetration into the concrete, and suggest SDU 2 concrete is highly resistant to sulfate attack compared to ordinary concrete. Physical properties of the SDU 2 concrete have not changed significantly from previous values. Therefore, the reduced ettringite formation appears to derive from changes in the concrete chemistry. The revised ionic concentrations in SDU 2 concrete pore water 
reported by SIMCO (2012) are much lower than previous values and the concrete mineral composition has also changed significantly.

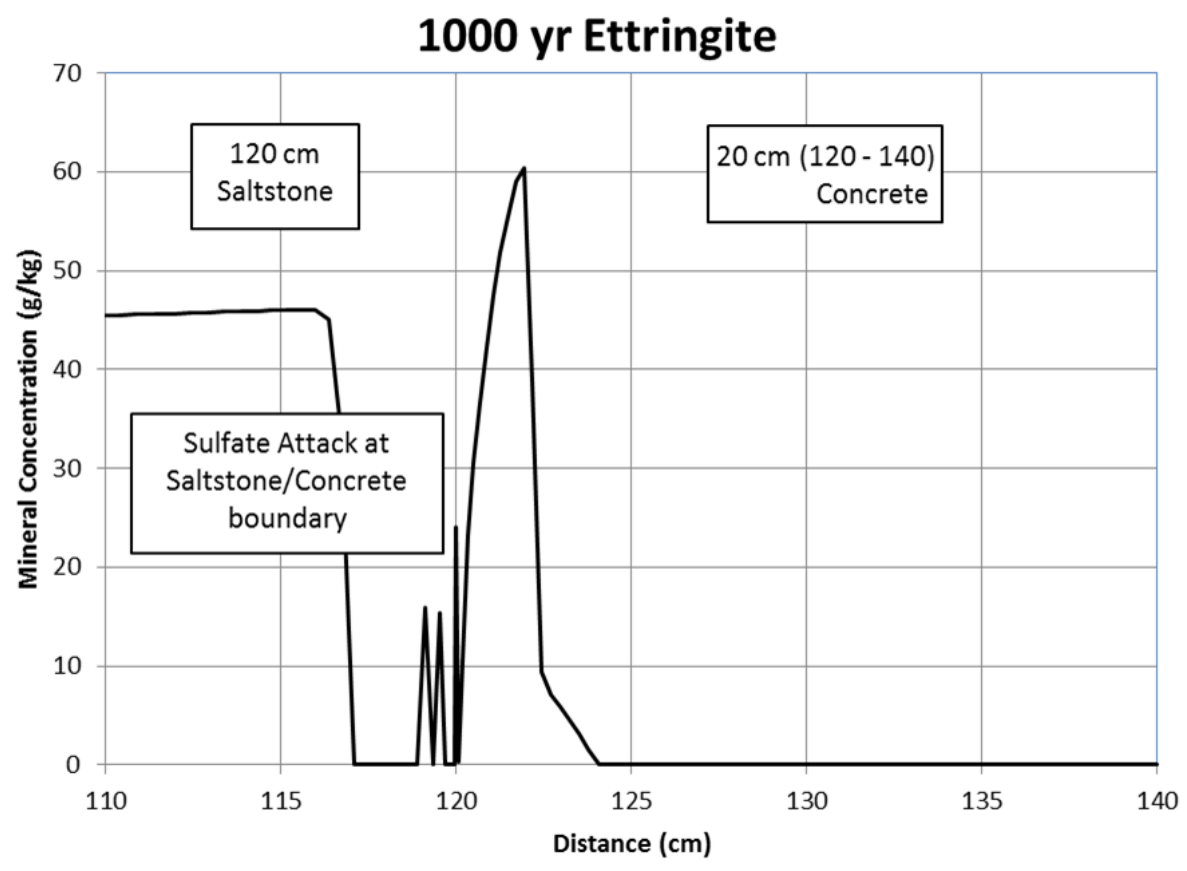

Figure 2-1. STADIUM prediction of sulfate attack on SDU 2 concrete at saltstone/concrete interface using default CBP Toolbox parameters.

The revised SIMCO saltstone and cement compositions were also used to perform a 1000 year STADIUM simulation of sulfate attack on $45 \mathrm{~cm}$ (18 in) of SDU 1/4 cement. The 45 $\mathrm{cm}$ thickness is representative of the SDU 1/4 wall. Results from this simulation are shown in Figure 2.3. The predicted ettringite front for this system is more similar to that obtained by previous STADIUM analyses, as shown in Figure 2.1.

Results from the STADIUM analyses using the latest SIMCO concrete and saltstone waste compositions are listed in Table 2.1. The ettringite penetration depth is conservatively defined as the furthest point of ettringite presence indicated by Figures 2.1 and 2.2. In comparison, SIMCO (2010) used the vertical face of the ettringite peak. STADIUM does not predict whether damage will occur, and thus does not alter transport properties in response to damage. To estimate failure times, physical damage (e.g., cracking, spalling) is assumed to coincide with the presence of ettringite in STADIUM simulations. To approximately account for the effect of physical damage on transport, the estimated time for complete concrete degradation is calculated using a simple linear extrapolation of the model calculated results at 1000 years assuming no degradation at time zero. That is, no credit is taken for the possibility that ettringite may penetrate as a diffusion front obeying Equation (1.5), which would lead to longer times for complete penetration. 
SRNL-STI-2013-00118, REVISION 0

Table 2-1. Results from STADIUM concrete degradation simulations.

\begin{tabular}{c|cccc} 
Concrete & $\begin{array}{c}\text { Ettringite } \\
\text { front depth* } \\
\text { at 1000 years } \\
\text { (a) }\end{array}$ & $\begin{array}{c}\text { Ettringite } \\
\text { front depth* } \\
\text { at 5000 years } \\
\text { (a) }\end{array}$ & Thickness & $\begin{array}{c}\text { Estimated Time for } \\
\text { Complete } \\
\text { Degradation }\end{array}$ \\
\hline SDU 2 & $0.5 \mathrm{~cm}$ & $1.5 \mathrm{~cm}$ & $20 \mathrm{~cm}$ & $40,000 \mathrm{yr}$ \\
SDU $1 / 4$ & $\begin{array}{c}5.5 \mathrm{~cm} \\
\text { * based on furthest point of ettringite penetration }\end{array}$ & $45 \mathrm{~cm}$ & $8,200 \mathrm{yr}$
\end{tabular}

In the 2009 Saltstone PA, the following empirical relationship was derived to calculate sulfate attack penetration depth, based on previous STADIUM calculations:

$$
x=A c^{B} t^{1 / 2}
$$

In Equation (2.1), $c$ is the molar concentration of sulfate in pore water and the coefficients $A$ and $B$ are 0.412 and 0.380 for SDU $1 / 4$ and 0.626 and 0.467 for SDU 2, respectively. These calculations involved a single layer of concrete with approximate properties based on a surrogate material. Application of this equation predicts degradation times of approximately 8,800 years for $20 \mathrm{~cm}$ of SDU 2 concrete and 69,000 years for $45 \mathrm{~cm}$ of SDU $1 / 4$ concrete. These results are almost the converse of those obtained with STADIUM using the revised saltstone and concrete compositions. These differences indicate the sensitivity of sulfate attack predictions to initial mineral composition (Samson 2010) and transport properties. The results presented in Figures 2.1 and 2.2 and Table 2.1 are considered more reliable because they involve a more realistic two-layer system and material properties have been updated using the best available characterization studies. 


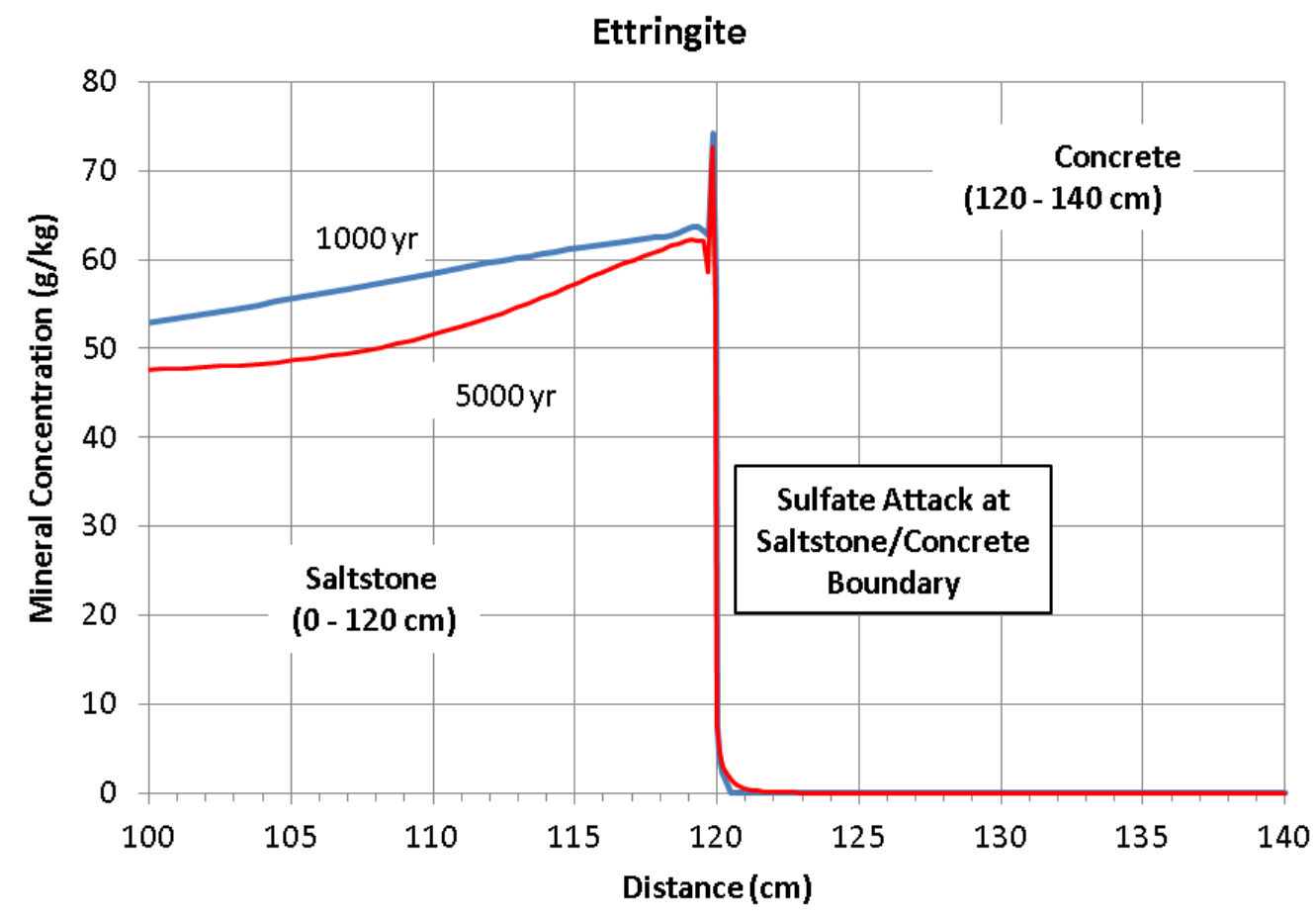

Figure 2-2. STADIUM prediction of sulfate attack on SDU 2 concrete at 1000 and 5000 years.

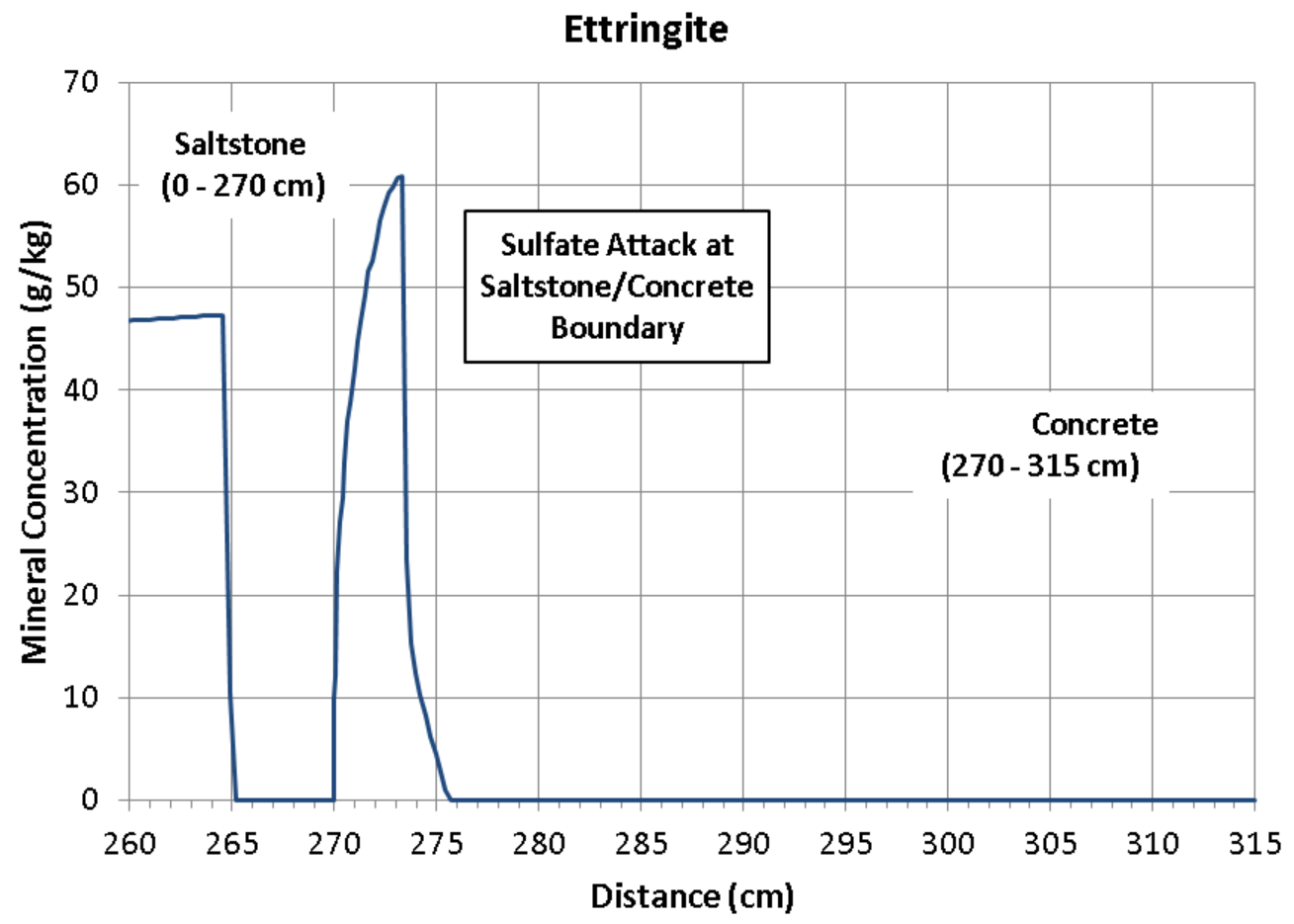

Figure 2-3. STADIUM prediction of sulfate attack on SDU 1/4 concrete at 1000 years. 
SRNL-STI-2013-00118, REVISION 0

\subsection{LXO Sulfate Attack}

Several sets of calculations were also performed using the LXO module in the CBP Toolbox to predict sulfate attack on SDU 1/4 concrete at thicknesses of 45 and $60 \mathrm{~cm}$ and SDU 2 concrete at thicknesses of 20 and $30 \mathrm{~cm}$. The smaller concrete thickness was representative of SDU 2 wall thickness while the larger value was representative of SDU $1 / 4$ floor thickness. The LXO calculations used the default concrete chemical compositions in the CBP Toolbox and revised mineral compositions based on the recent SIMCO analysis (SIMCO, 2012). Except as noted below, the concrete parameters contained in the initial CBP Toolbox release such as thermal conductivity, specific heat, and rate of hydration were also used in the analysis. The initial sulfate concentration in the fluid phase was set to $0.1 \mathrm{M}$.

The use of Orchestra (the modeling part of LXO) to model sulfate attack on cementitious material is discussed in detail by Sarkar et al. (2009). The model uses a parameter designated as the "fractional porosity" $(b)$ which is defined to be the fraction of the pore volume that must be filled with mineral products from the chemical reactions that occur during concrete aging before cracking and concrete damage occur. The larger the fractional porosity the more pore volume is available for solid product deposition and the less damage occurs. Results are very sensitive to this parameter.

Sarkar et al. (2009) concluded that in general the optimal value for fractional porosity is $b$ $=0.3$ based on model calibration and literature review. The main effect of fractional porosity in the model is to cause an increase in the diffusion coefficient, which accelerates delivery of sulfate to the reaction front and ettringite penetration. The model implicitly assumes saturated conditions (i.e. pores in the concrete are filled with water) for this calculation. However, any cracks that form during sulfate attack are expected to be unsaturated under Saltstone conditions, based on Equation (3.10) and surrounding discussion in Section 3.0. Such "dry" cracks would likely cause a smaller increase in diffusion coefficient compared to saturated cracks, or even impede diffusion (Seol et al. 2003). Unsaturated cracks and slower diffusion compared to saturated conditions can be approximately accounted for by increasing fractional porosity above 0.3 . Based on engineering judgment, the current study was performed using a fractional porosity of 0.45 as the nominal value representative of unsaturated conditions with minimum (conservative estimate) and maximum (best estimate) values of 0.3 and 0.6 , respectively.

The progression of an ettringite mineral front into the concrete coincides with the extent of concrete damage according to the LXO sulfate attack model. The ettringite front also coincides with a decrease in concrete porosity as predicted by the LXO model which would be indicative of concrete damage. After an initial period of rapid penetration, the rate of progression of the ettringite front predicted by LXO was found to be approximately linear, in contrast to a square root of time dependence indicated by Equations (1.2) and (1.5) for fixed diffusivity. Results showing ettringite mineralization in the concrete for the case of $30 \mathrm{~cm}$ of SDU 2 concrete with a fractional porosity of 0.6 at 100 year intervals are shown in Figure 2.4. The maximum ettringite penetration depth is plotted as a function of time in Figure 2.5 where the linear progression between 100 and 500 years is apparent. LXO simulations were performed for either 350 years or 500 
years. Based on the results shown in Figure 2.5, the time for complete concrete degradation was estimated from the penetration depth predicted at the end of the simulation using linear extrapolation.

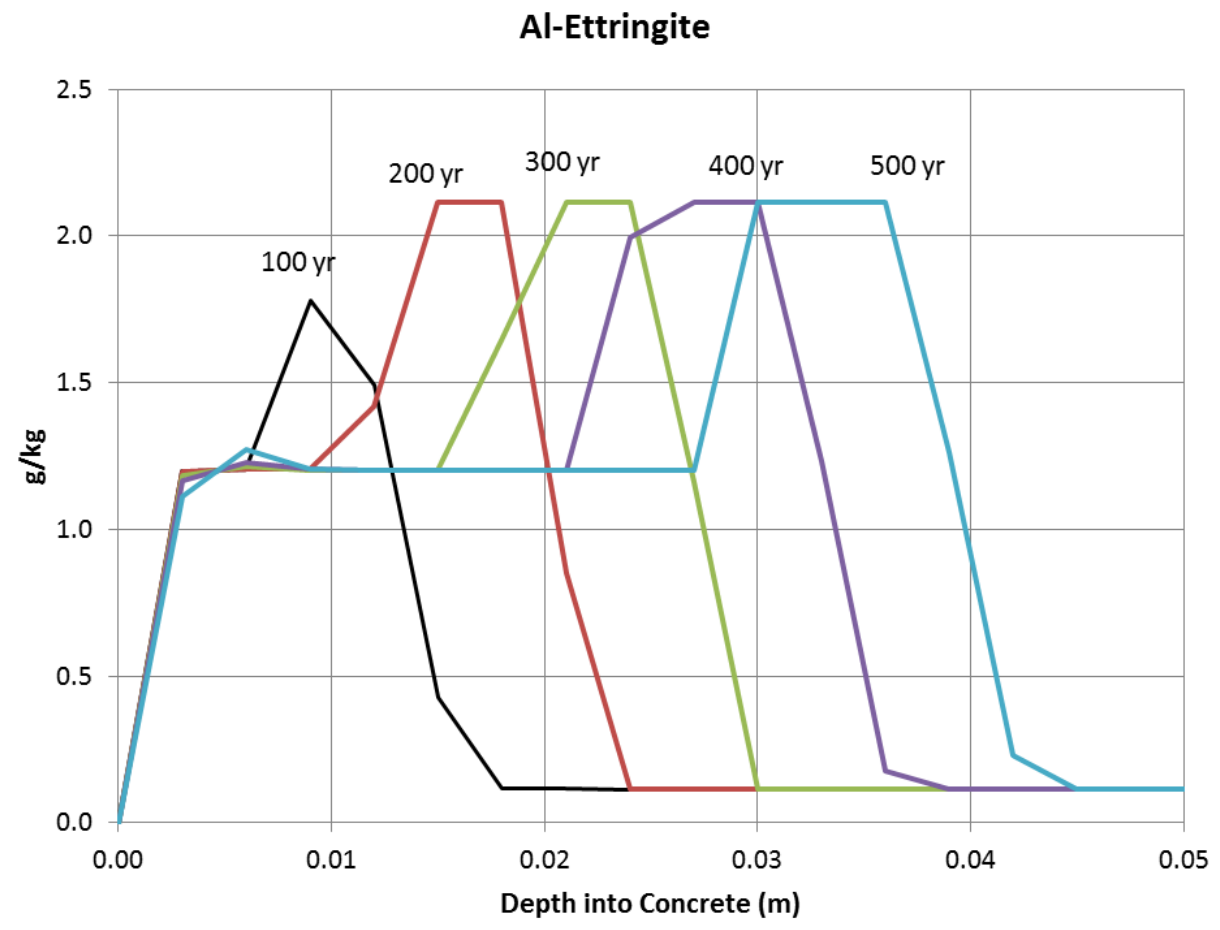

Figure 2-4. Ettringite front penetration as a function of time for $30 \mathrm{~cm}$ of SDU 2 concrete with a fractional porosity of 0.6 .

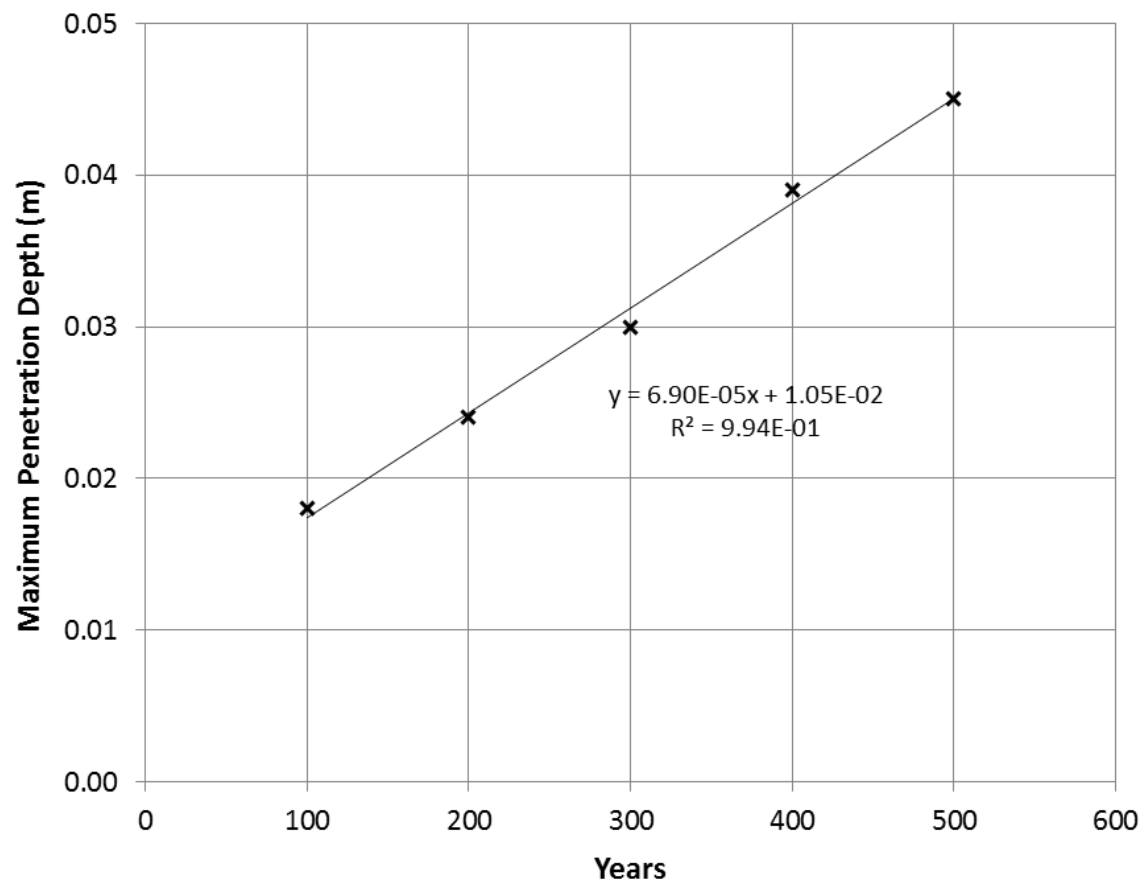

Figure 2-5. Maximum ettringite front penetration as a function of time for $30 \mathrm{~cm}$ of SDU 2 concrete with a fractional porosity of $\mathbf{0 . 6}$. 


\subsubsection{LXO Simulation of Sulfate Attack on SDU 2 Concrete}

SDU 2 calculations were performed for a concrete thickness of $20 \mathrm{~cm}$, which is representative of the SDU 2 wall thickness, and for a concrete thickness of $30 \mathrm{~cm}$, representative of the SDU 2 floor. An initial concrete porosity of 0.115 was used in these calculations and the VCT ("Vault Concrete Two", SDU 2 mix) concrete composition was selected through the CBP user interface. Results for the $20 \mathrm{~cm}$ concrete thickness are shown in Figure 2.6 for the three values of fractional porosity specified and results for the $30 \mathrm{~cm}$ thickness are shown in Figure 2.7. It was intended to run all of the simulations for 500 years; however, when the front progressed beyond $50 \%$ of the concrete thickness, the LXO code had difficulty converging. Therefore, to obtain a consistent set of results, all SDU 2 calculations for $20 \mathrm{~cm}$ thickness were performed for only 350 years.

Linear extrapolation was used to estimate a time for complete concrete degradation from the front penetration times shown in Figures 2.6 and 2.7. Results of these calculations are listed in Table 2.2 and 2.3 for the $20 \mathrm{~cm}$ and $30 \mathrm{~cm}$ concrete thickness, respectively. The degradation times were then plotted as a function of fractional porosity and fit to a polynomial function. The fitting function was used to interpolate degradation times at intermediate values of the fractional porosity with the results plotted in Figure 2.8. The results shown in Figure 2.8 illustrate the sensitivity of the estimate of degradation to the fractional porosity. Beyond a fractional porosity of 0.5 , the curves increase sharply.

Table 2-2. SDU 2 LXO sulfate attack calculations for $20 \mathrm{~cm}$ of concrete.

\begin{tabular}{cc|ccc}
$\begin{array}{c}\text { Fractional } \\
\text { Porosity }\end{array}$ & Years & $\begin{array}{c}\text { Front Depth } \\
(\mathrm{cm})\end{array}$ & $\begin{array}{c}\text { Fraction } \\
\text { Degraded }\end{array}$ & $\begin{array}{c}\text { Estimated Time } \\
\text { for Complete } \\
\text { Degradation }\end{array}$ \\
\hline 0.60 & 350 & 3.8 & 0.190 & 1842 \\
0.45 & 350 & 7.4 & 0.370 & 946 \\
0.30 & 350 & 9.4 & 0.470 & 745
\end{tabular}

Table 2-3. SDU 2 LXO sulfate attack calculations for $30 \mathrm{~cm}$ of concrete.

\begin{tabular}{cc|ccc}
$\begin{array}{c}\text { Fractional } \\
\text { Porosity }\end{array}$ & Years & $\begin{array}{c}\text { Front Depth } \\
(\mathrm{cm})\end{array}$ & $\begin{array}{c}\text { Fraction } \\
\text { Degraded }\end{array}$ & $\begin{array}{c}\text { Estimated Time } \\
\text { for Complete } \\
\text { Degradation }\end{array}$ \\
\hline 0.60 & 500 & 4.5 & 0.150 & 3333 \\
0.45 & 500 & 8.4 & 0.280 & 1786 \\
0.30 & 500 & 11.1 & 0.370 & 1351
\end{tabular}




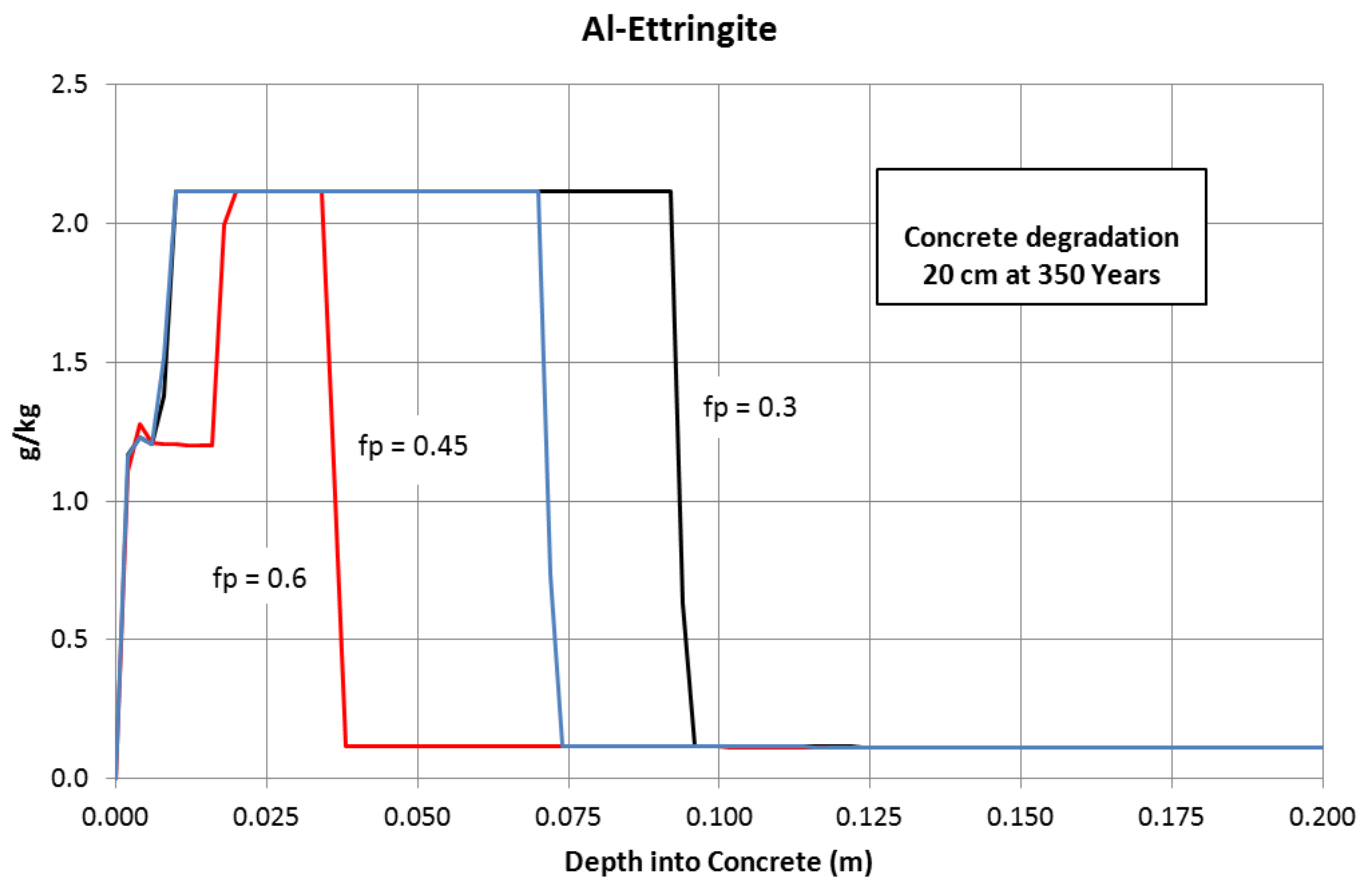

Figure 2-6. Ettringite front penetration as a function of concrete fractional porosity for $20 \mathrm{~cm}$ SDU 2 concrete.

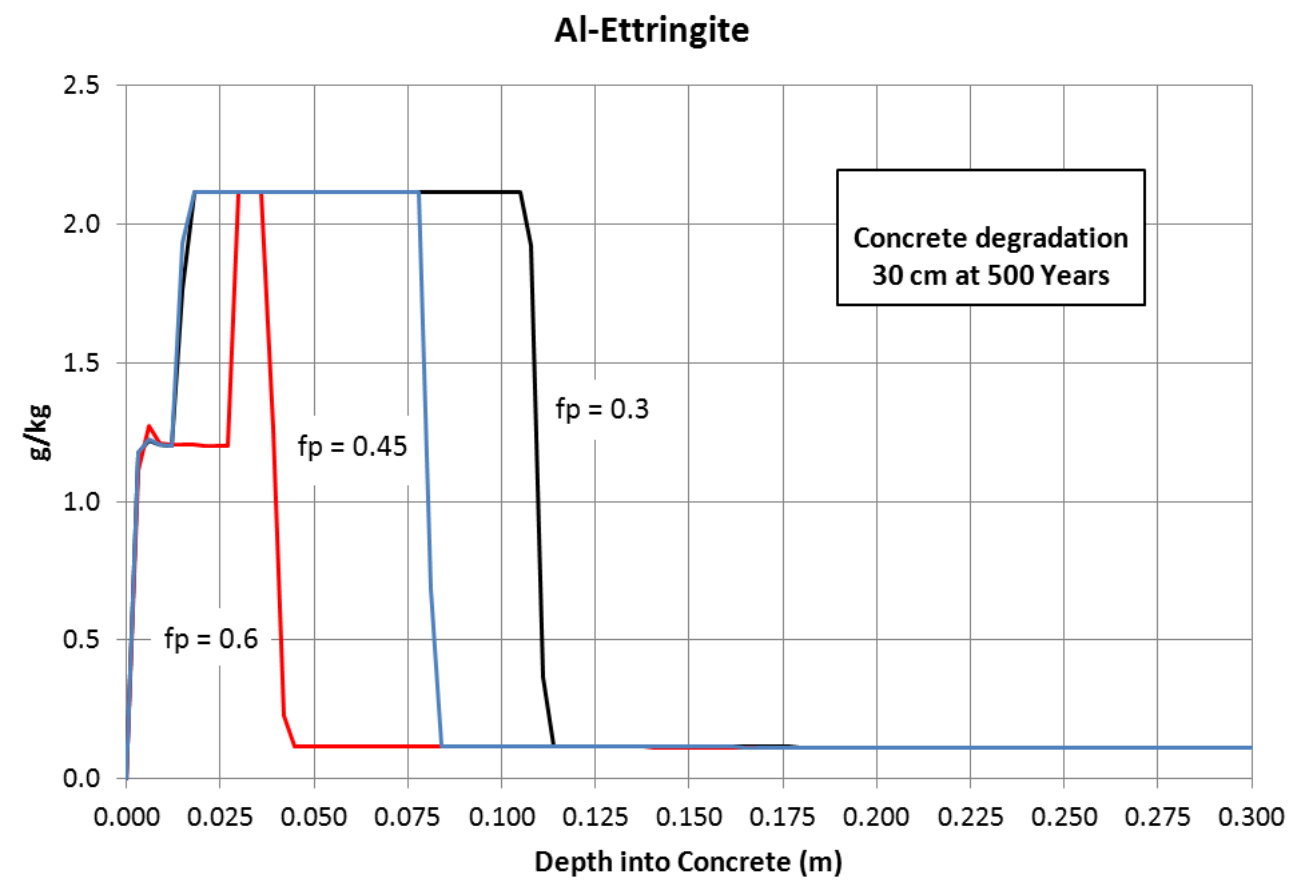

Figure 2-7. Ettringite front penetration as a function of concrete fractional porosity for $30 \mathrm{~cm}$ SDU 2 concrete. 


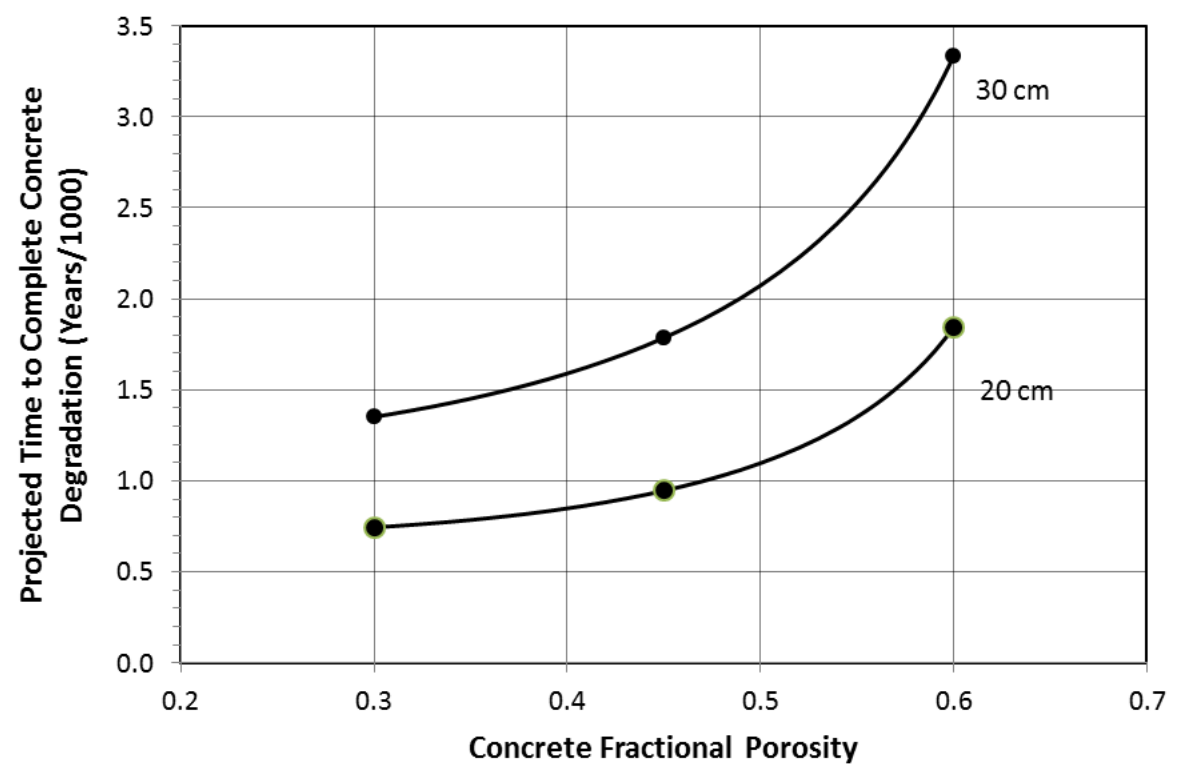

Figure 2-8. Predicted times for $100 \%$ SDU 2 concrete degradation as a function of fractional porosity.

\subsubsection{LXO Simulation of Sulfate Attack on SDU 1/4 Concrete}

SDU $1 / 4$ calculations were performed for a concrete thickness of $45 \mathrm{~cm}$, which is representative of the SDU $1 / 4$ wall thickness, and for a concrete thickness of $60 \mathrm{~cm}$, representative of the SDU 1/4 floor. An initial concrete porosity of 0.12 was used in these calculations and the VCO ("Vault Concrete One", SDU 1/4 mix) concrete composition was selected through the CBP Toolbox user interface. Results for the $45 \mathrm{~cm}$ concrete thickness are shown in Figure 2.9 for the three values of fractional porosity specified and results for the $60 \mathrm{~cm}$ thickness are shown in Figure 2.10. All simulations were performed to simulate 500 years.

Linear extrapolation was used to calculate a time for complete concrete degradation from the front penetration times shown in Figures 2.9 and 2.10. Results from these calculations are listed in Table 2.4 and 2.5 for the $45 \mathrm{~cm}$ and $60 \mathrm{~cm}$ concrete thickness, respectively. As was done with the SDU 2 results, the degradation times were then plotted as a function of fractional porosity and fit to a smooth polynomial function. This fitting function was used to interpolate degradation times at intermediate values of the fractional porosity with the results plotted in Figure 2.11. 
Table 2-4. SDU 1/4 LXO sulfate attack calculations for $45 \mathrm{~cm}$ of concrete.

\begin{tabular}{cc|ccc}
$\begin{array}{c}\text { Fractional } \\
\text { Porosity }\end{array}$ & Years & $\begin{array}{c}\text { Front Depth } \\
(\mathrm{m})\end{array}$ & $\begin{array}{c}\text { Fraction } \\
\text { Degraded }\end{array}$ & $\begin{array}{c}\text { Estimated Time } \\
\text { for Complete } \\
\text { Degradation }\end{array}$ \\
\hline 0.60 & 500 & 0.076 & 0.170 & 2941 \\
0.45 & 500 & 0.189 & 0.420 & 1190 \\
0.30 & 500 & 0.230 & 0.510 & 980
\end{tabular}

Table 2-5. SDU $1 / 4$ LXO sulfate attack calculations for $60 \mathrm{~cm}$ of concrete.

\begin{tabular}{cc|ccc}
$\begin{array}{c}\text { Fractional } \\
\text { Porosity }\end{array}$ & Years & $\begin{array}{c}\text { Front Depth } \\
(\mathrm{m})\end{array}$ & $\begin{array}{c}\text { Fraction } \\
\text { Degraded }\end{array}$ & $\begin{array}{c}\text { Estimated Time } \\
\text { for Complete } \\
\text { Degradation }\end{array}$ \\
\hline 0.60 & 500 & 0.072 & 0.120 & 4167 \\
0.45 & 500 & 0.162 & 0.270 & 1852 \\
0.30 & 500 & 0.222 & 0.370 & 1351
\end{tabular}

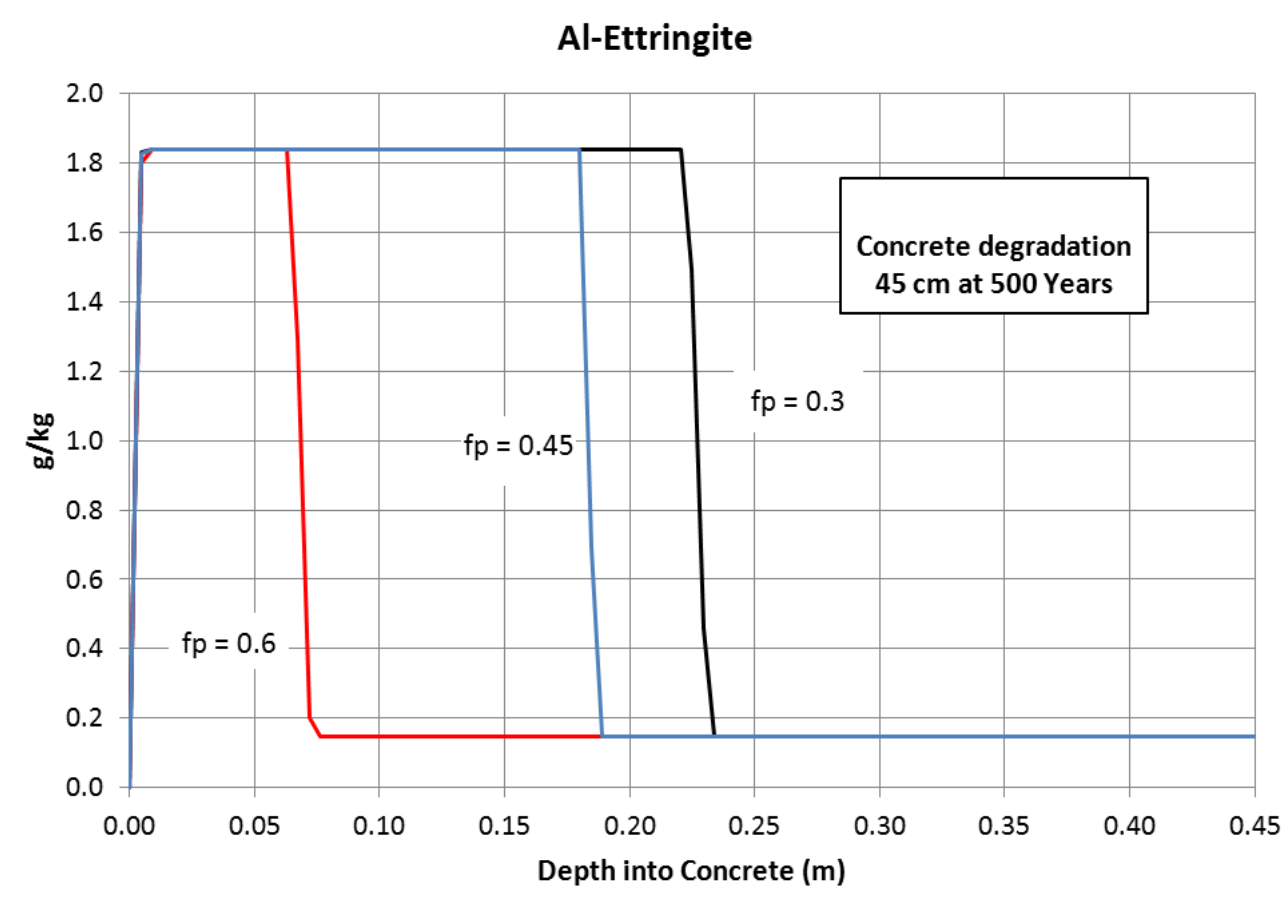

Figure 2-9. Ettringite front penetration as a function of concrete fractional porosity for $45 \mathrm{~cm}$ SDU 1/4 concrete. 


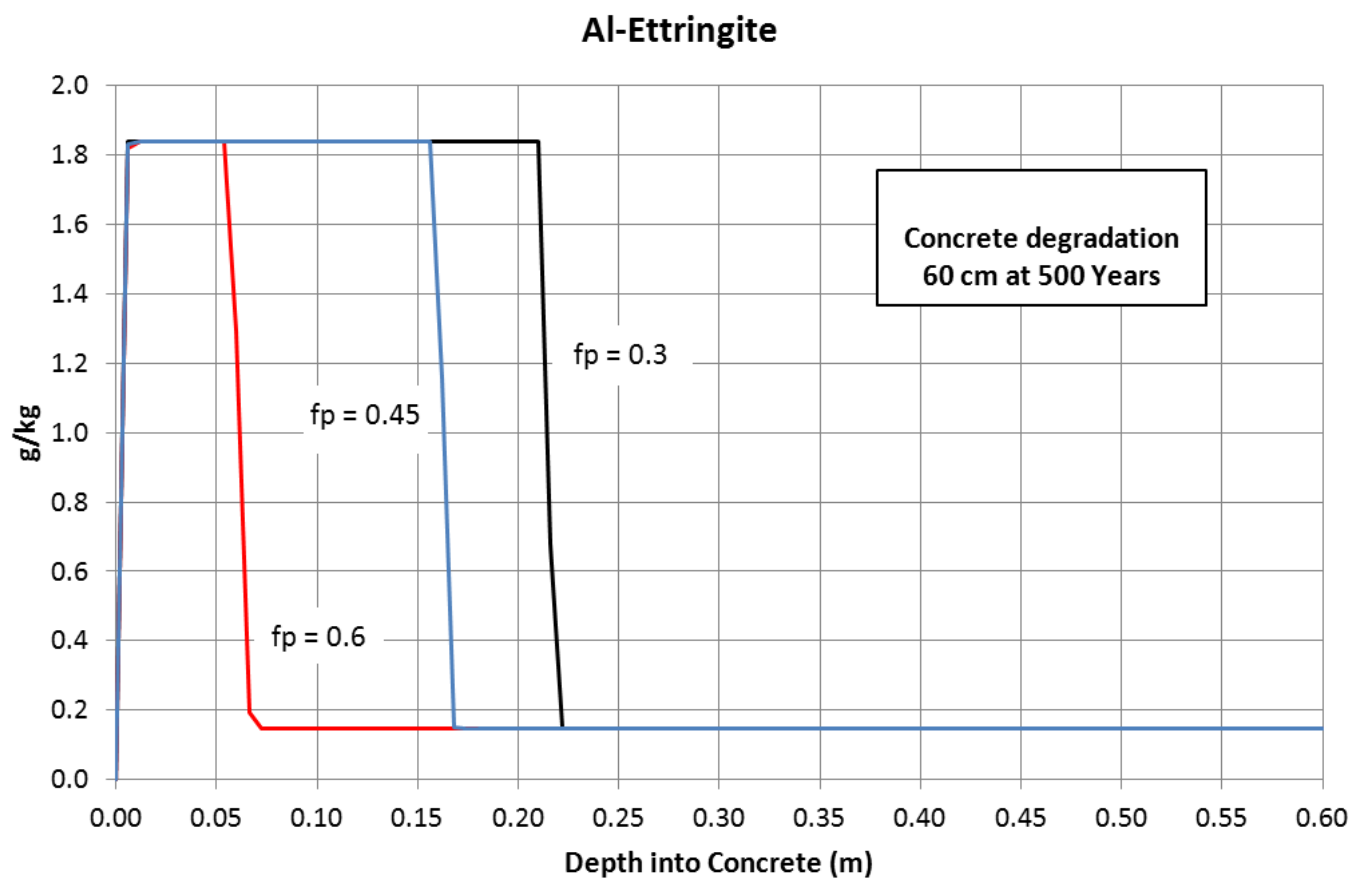

Figure 2-10. Ettringite front penetration as a function of concrete fractional porosity for $60 \mathrm{~cm}$ SDU $1 / 4$ concrete.

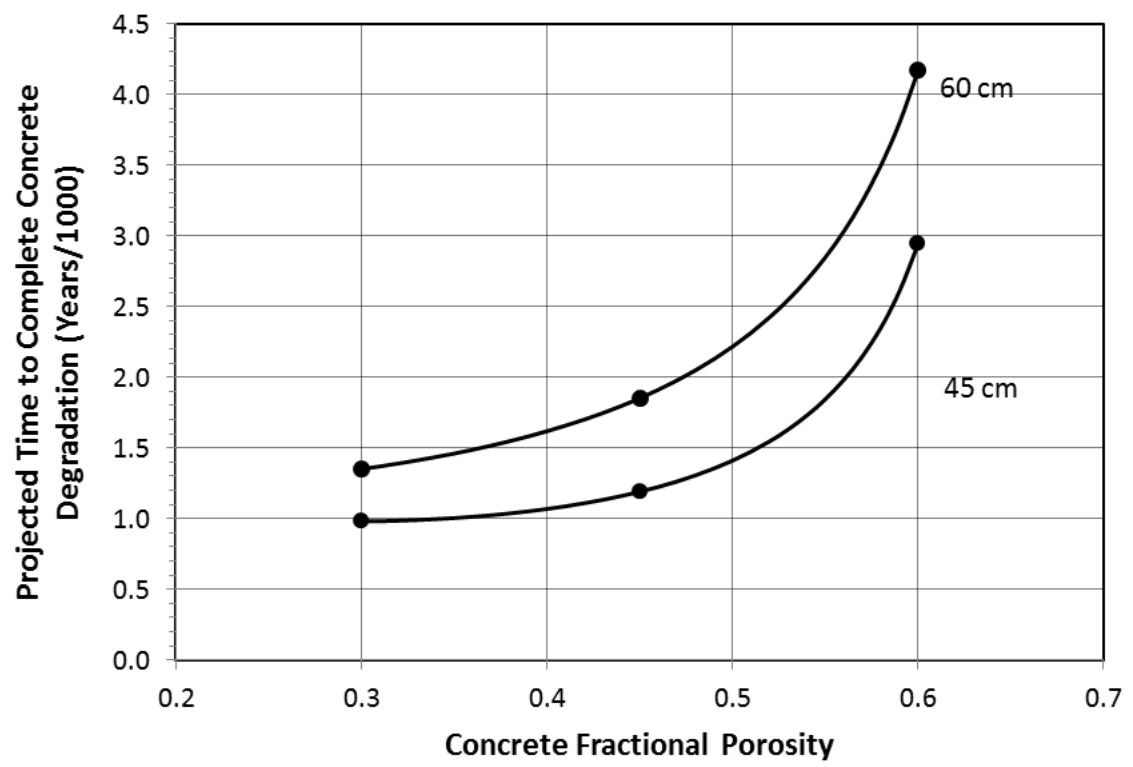

Figure 2-11. Predicted time for $100 \%$ SDU $1 / 4$ concrete degradation as a function of fractional porosity. 


\subsection{Sulfate Attack Results}

From the analyses described in the preceding sections, the LXO model was found to predict faster concrete degradation from sulfate attack than was seen in the STADIUM simulations, in part because the model modifies transport properties based on predicted damage. LXO incorporates mineral availabilities that are generally less than $100 \%$, which leads to faster depletion of solid reactants. STADIUM and LXO also assume different initial chemical compositions, which affects the results (Sarkar et al. 2011). Therefore, lacking long term experimental data to confirm either model, the more conservative LXO results shown in Tables 2.2 through 2.5 are recommended for estimating concrete degradation from sulfate attack.

Degradation times obtained using a fractional porosity of 0.45 represent nominal values while the degradation times obtained with fractional porosities of 0.3 and 0.6 represent conservative and best estimate values, respectively. With this approach, the best estimate of the degradation time is approximately twice the nominal, while the nominal and conservative values differ less. Therefore, a large variation in the estimated degradation time is not introduced into the analysis by choosing a fractional porosity of 0.45 for the nominal value compared to 0.3 for fully saturated conditions.

While degradation times are presented in the summary tables for the thicknesses involved in the simulations, failure times for other thicknesses will be needed in Section 5.0, in which failure times are defined for the various SDU 1, 2, and 4 concrete components. To this end, general degradation rates are defined from simulation results using the linear relationship

$$
A_{\ell}=\frac{x_{0}}{t_{0}}
$$

instead of Equation (1.7), which was found to be not applicable to LXO simulation results. Here $\left(t_{0}, x_{0}\right)$ represents a selected penetration time and depth from a numerical simulation and the subscript $\ell$ denotes a linear rate constant to distinguish it from the square of time rate constants defined by Equations (1.6) and (1.7). The time $t_{0}$ associated with another penetration depth $x_{0}$ is then

$$
t_{0}=\frac{x_{0}}{A_{\ell}}
$$

Somewhat faster degradation rates were observed for a thinner model domain (e.g. 20 versus $30 \mathrm{~cm}$ ), so Table 2.2 and Table 2.4 are used to generate linear degradation rates, which are presented in Table 2.6.

Calculation of specific failure times is provided in Section 5.0. 
Table 2-6. Sulfate attack rates for SDU 2 and SDU 1/4 concrete.

\begin{tabular}{|c|c|c|c|c|c|c|}
\hline Parameter & $\begin{array}{l}\mathrm{SDU} \\
2 \mathrm{CE}^{1}\end{array}$ & $\begin{array}{c}\mathrm{SDU} \\
2 \mathrm{NV}^{3}\end{array}$ & $\begin{array}{l}\mathrm{SDU} \\
2 \mathrm{BE}^{3}\end{array}$ & $\begin{array}{c}\text { SDU } 1 / 4 \\
\text { CE }^{1}\end{array}$ & $\begin{array}{c}\text { SDU 1/4 } \\
\mathrm{NV}^{2}\end{array}$ & $\begin{array}{c}\text { SDU } 1 / 4 \\
\mathrm{BE}^{3}\end{array}$ \\
\hline Fractional porosity, $b$ & 0.3 & 0.45 & 0.6 & 0.3 & 0.45 & 0.6 \\
\hline $\begin{array}{l}\text { Penetration depth, } x_{0} \\
(\mathrm{~cm})\end{array}$ & 9.4 & 7.4 & 3.8 & 23 & 18.5 & 7.7 \\
\hline Penetration time, $t_{0}(\mathrm{yr})$ & 350 & 350 & 350 & 500 & 500 & 500 \\
\hline $\begin{array}{l}\text { Linear rate constant, } A_{\ell} \\
(\mathrm{cm} / \mathrm{yr})\end{array}$ & 0.027 & 0.021 & 0.011 & 0.046 & 0.037 & 0.015 \\
\hline
\end{tabular}

\subsection{CARBONATION}

Carbonation, more properly termed carbonatation, commonly refers to the reaction of carbon dioxide with calcium hydroxide (Portlandite) to form calcium carbonate (calcite):

$$
\mathrm{Ca}(\mathrm{OH})_{2}+\mathrm{H}_{2} \mathrm{O}+\mathrm{CO}_{2} \rightarrow \mathrm{CaCO}_{3}+2 \mathrm{H}_{2} \mathrm{O}
$$

More generally, carbonation in the context of concrete may include other reactions of carbon dioxide with calcium-bearing minerals, such as calcium-silicate-hydrate (CSH). Carbonation increases mechanical strength and decreases alkalinity to a $\mathrm{pH}$ around 8.5 in cementitious materials. While the former is generally beneficial, corrosion of embedded steel accelerates as $\mathrm{pH}$ approaches carbonated conditions, approximately $\mathrm{pH}<10$. The volume of the corrosion products far exceeds that of the uncorroded steel, which typically introduces sufficient internal pressure to cause cracking and spalling of the surrounding concrete. Most concrete components of the various SDUs contain reinforcing steel, notable exceptions being the upper and lower mudmats in the SDU 2 design. Saltstone also contains embedded steel in the form of support columns (SDU 2 and 4) and roof trusses (SDU 4).

Papadakis et al. (1989) developed an analytical solution for carbonation penetration depth with the same basic form as Equation (1.2). Using the nomenclature of this report, the expression is

$$
x=\left[\frac{2 \theta D_{e} c_{C O_{2} t}}{c_{C a(O H)_{2}}+3 c_{C S H}}\right]^{1 / 2}
$$

where

$$
\begin{aligned}
x & =\text { penetration depth }[\mathrm{cm}] \\
\theta & =\text { gas content, } \operatorname{Sn}\left[\mathrm{cm}^{3} \text { phase } / \mathrm{cm}^{3} \text { total }\right] \\
D_{e} & =\text { effective diffusion coefficient for gas phase, } \tau D_{m}\left[\mathrm{~cm}^{2} / \mathrm{yr}\right]
\end{aligned}
$$




$$
\begin{aligned}
& C_{\mathrm{CO}_{2}}=\text { carbon dioxide concentration }\left[\mathrm{mol} / \mathrm{cm}^{3} \text { gas }\right] \\
& t=\text { elapsed time }[\mathrm{yr}] \\
& C_{\mathrm{Ca}(\mathrm{OH})_{2}}=\text { Portlandite concentration }\left[\mathrm{mol} / \mathrm{cm}^{3} \text { total }\right] \\
& c_{\mathrm{CSH}}=\mathrm{CSH} \text { concentration, } \mathrm{CSH} \equiv 3 \mathrm{CaO} \cdot 2 \mathrm{SiO}_{2} \cdot 3 \mathrm{H}_{2} \mathrm{O}\left[\mathrm{mol} / \mathrm{cm}^{3} \text { total }\right] .
\end{aligned}
$$

In the context of Equation (1.6), $c_{\mathrm{Ca}(\mathrm{OH})_{2}}+3 c_{\mathrm{CSH}}=(1-n) \rho_{\mathrm{S}} R$. Equation (3.1) considers only transport of carbon dioxide through the gas phase, which is appropriate for unsaturated concrete in typical applications. However, fully saturated conditions are also of interest for the SDF and Equation (3.1) can be generalized to include delivery of dissolved carbon dioxide to the reaction front as follows

$$
x=\left[\frac{2\left(\theta_{g} D_{e, g} c_{C O_{2,}}+\theta_{\ell} D_{e, \ell} c_{C O_{2, \ell}}\right) t}{c_{C a}}\right]^{1 / 2}=A t^{1 / 2}
$$

where the subscripts $g$ and $\ell$ denote the gas and liquid phases, respectively, and

$$
A \equiv\left[\frac{2\left(\theta_{g} D_{e, g} c_{C O_{2, g}}+\theta_{\ell} D_{e, \ell} c_{C O_{2}, \ell}\right)}{c_{C a}}\right]^{1 / 2}
$$

Also, the denominator of Equation (3.1) is equivalent to the cumulative molar concentration of $\mathrm{Ca}$ in $\mathrm{Ca}(\mathrm{OH})_{2}$ and $\mathrm{CSH}$, and denoted by $c_{\mathrm{Ca}}$ in these equations. Equation (3.2) is used to predict carbonation depth under saturated and unsaturated conditions in this study.

Millings (2012) estimated the average and median partial pressure of $\mathrm{CO}_{2}$ in the vadose zone to be roughly $0.01 \mathrm{~atm}$ at the Savannah River Site, compared to an atmospheric partial pressure of $0.00039 \mathrm{~atm}$. Using the ideal gas law at $20^{\circ} \mathrm{C}$, the molar concentration of carbon dioxide in the vadose zone becomes $4.16 \mathrm{E}-07 \mathrm{~mol} / \mathrm{cm}^{3}$ gas. The concentration of dissolved $\mathrm{CO}_{2}$ in soil moisture can be estimated from Henry's law written in the form

$$
p=k_{H} c_{a q}
$$

where $p=$ partial pressure (atm), $c_{a q}=$ aqueous concentration $(\mathrm{mol} / \mathrm{L})$, and $k_{H}=29.41$ $\mathrm{L} \cdot \mathrm{atm} / \mathrm{mol}$ for carbon dioxide (http://en.wikipedia.org/wiki/Henry's_law). For a partial pressure of $0.01 \mathrm{~atm}$, the result is $c_{a q}=3.40 \mathrm{E}-07 \mathrm{~mol} / \mathrm{cm}^{3}$ liquid. The transport properties and solid phase concentrations for the SDU 1/4 floor and wall concrete and SDU 2 concrete are available from the Saltstone PA (SRR 2009) and a more recent characterization report, SIMCO (2012). Similar data for the Saltstone grout are provided in SRR (2009) and SIMCO (2010). These input data to Equations (3.2) and (3.3) are summarized in Table 3-1. The solid phase concentration of calcium in SDU 1 and 4 roof concrete is approximated by scaling the SDU $1 / 4$ floor/wall concrete value using the $\mathrm{CaO}$ ratios computed in Table 3-2 based on the composition (SIMCO 2012, Table 3; SRR 2009, Tables 3.2-1 and 3.2-2) of the unhydrated binders. 
SRNL-STI-2013-00118, REVISION 0

Table 3-1. Input data and rate constants for carbonation calculations.

\begin{tabular}{|c|c|c|c|c|c|c|}
\hline Parameter & SDU 2 & $S D U 1 / 4$ & $\begin{array}{l}\text { SDU } 4 \\
\text { Roof }\end{array}$ & $\begin{array}{l}\text { SDU } 1 \\
\text { Roof }\end{array}$ & Saltstone & Units \\
\hline$p_{\mathrm{CO}_{2}}$ (a) & 0.01 & 0.01 & 0.01 & 0.01 & 0.01 & atm \\
\hline$c_{\mathrm{CO}_{2}, \mathrm{~g}}(\mathrm{~b})$ & $4.16 \mathrm{e}-7$ & $4.16 \mathrm{e}-7$ & $4.16 \mathrm{e}-7$ & $4.16 \mathrm{e}-7$ & $4.16 \mathrm{e}-7$ & $\mathrm{~mol} / \mathrm{cm}^{3}$ gas \\
\hline$c_{C_{2}, \ell}(\mathrm{c})$ & $3.40 \mathrm{e}-7$ & $3.40 \mathrm{e}-7$ & $3.40 \mathrm{e}-7$ & $3.40 \mathrm{e}-7$ & $3.40 \mathrm{e}-7$ & $\mathrm{~mol} / \mathrm{cm}^{3}$ liquid \\
\hline$n(\mathrm{~d})$ & 0.11 & 0.12 & 0.136 & 0.145 & 0.58 & $\begin{array}{l}\mathrm{cm}^{3} \text { void } / \mathrm{cm}^{3} \\
\text { total }\end{array}$ \\
\hline$\rho_{b}(\mathrm{~d})$ & 2.22 & 2.24 & 2.21 & 2.20 & 1.01 & $\mathrm{~g} / \mathrm{cm}^{3}$ total \\
\hline$D_{m, g}(\mathrm{e})$ & 0.165 & 0.165 & 0.165 & 0.165 & 0.165 & $\mathrm{~cm}^{2} / \mathrm{s}$ \\
\hline$\tau(\mathrm{f}, \mathrm{g})$ & $\begin{array}{l}0.005 \\
\text { (f) }\end{array}$ & $\begin{array}{l}0.008 \\
\text { (f) }\end{array}$ & $\begin{array}{l}0.008 \\
\text { (f) }\end{array}$ & $\begin{array}{l}0.008 \\
\text { (f) }\end{array}$ & $\begin{array}{l}0.014 \\
\text { (g) }\end{array}$ & - \\
\hline$D_{e, g}(\mathrm{~h})$ & $8.25 \mathrm{e}-4$ & $1.32 \mathrm{e}-3$ & $1.32 \mathrm{e}-3$ & $1.32 \mathrm{e}-3$ & $2.31 \mathrm{e}-3$ & $\mathrm{~cm}^{2} / \mathrm{s}$ \\
\hline$D_{e, \ell}(\mathrm{d}, \mathrm{i})$ & $\begin{array}{l}5.0 \mathrm{e}-8 \\
\text { (d) }\end{array}$ & $\begin{array}{l}5.0 \mathrm{e}-8 \\
\text { (d) }\end{array}$ & $\begin{array}{c}1.0 \mathrm{e}-7 \\
\text { (d) }\end{array}$ & $\begin{array}{c}1.0 \mathrm{e}-7 \\
\text { (d) }\end{array}$ & $\begin{array}{l}1.0 \mathrm{e}-8 \\
\text { (i) }\end{array}$ & $\mathrm{cm}^{2} / \mathrm{s}$ \\
\hline $\begin{array}{r}{\left[\mathrm{Ca}(\mathrm{OH})_{2}\right]} \\
(\mathrm{f}, \mathrm{g})\end{array}$ & $\begin{array}{c}0 \\
\text { (f) }\end{array}$ & $\begin{array}{l}7.2 \\
\text { (f) }\end{array}$ & - & - & $\begin{array}{c}0 \\
\text { (g) }\end{array}$ & $\mathrm{g} / \mathrm{kg}$ \\
\hline$M_{\mathrm{Ca}(\mathrm{OH})_{2}}(\mathrm{j})$ & 74 & 74 & - & - & 74 & $\mathrm{~g} / \mathrm{mol}$ \\
\hline$c_{\mathrm{Ca}(\mathrm{OH})_{2}}(\mathrm{k})$ & 0 & $2.18 \mathrm{e}-4$ & - & - & 0 & $\mathrm{~mol} / \mathrm{cm}^{3}$ total \\
\hline$[\mathrm{CSH}](\mathrm{f}, \mathrm{g})$ & $\begin{array}{l}81.2 \\
\text { (f) }\end{array}$ & $\begin{array}{l}118.8 \\
\text { (f) }\end{array}$ & - & - & $\begin{array}{l}147.4 \\
\text { (g) }\end{array}$ & $\mathrm{g} / \mathrm{kg}$ \\
\hline$M_{C S H}(\mathrm{l})$ & 182.1 & 182.1 & - & - & 182.1 & $\mathrm{~g} / \mathrm{mol}$ \\
\hline$c_{C S H}(\mathrm{~m})$ & $9.90 \mathrm{e}-4$ & $1.46 \mathrm{e}-3$ & - & - & $8.18 \mathrm{e}-4$ & $\mathrm{~mol} / \mathrm{cm}^{3}$ total \\
\hline$c_{C a}(\mathrm{n}, \mathrm{o})$ & $\begin{array}{c}1.63 \mathrm{e}-3 \\
\text { (n) }\end{array}$ & $\begin{array}{l}2.63 e-3 \\
\text { (n) }\end{array}$ & $\begin{array}{l}2.11 \mathrm{e}-3 \\
\text { (o) }\end{array}$ & $\begin{array}{l}1.82 \mathrm{e}-3 \\
\text { (o) }\end{array}$ & $\begin{array}{c}1.35 \mathrm{e}-3 \\
\text { (n) }\end{array}$ & $\mathrm{mol} / \mathrm{cm}^{3}$ total \\
\hline Best estimate & $B E$ & $B E$ & $B E$ & $B E$ & $B E$ & \\
\hline$S_{g}(\mathrm{p})$ & $\begin{array}{l}6.6 \mathrm{e}-6 \\
(\sim 0)\end{array}$ & $\begin{array}{l}6.6 \mathrm{e}-6 \\
(\sim 0)\end{array}$ & $\begin{array}{l}6.6 \mathrm{e}-6 \\
(\sim 0)\end{array}$ & $\begin{array}{l}6.6 \mathrm{e}-6 \\
(\sim 0)\end{array}$ & 0.0017 & $\begin{array}{l}\mathrm{cm}^{3} \text { gas / } \\
\mathrm{cm}^{3} \text { void }\end{array}$ \\
\hline$S_{\ell}(\mathrm{q})$ & 1 & 1 & 1 & 1 & 0.9983 & $\begin{array}{l}\mathrm{cm}^{3} \text { liquid / } \\
\mathrm{cm}^{3} \text { void }\end{array}$ \\
\hline$\theta_{g}(\mathrm{r})$ & $7.2 \mathrm{e}-7$ & $7.9 \mathrm{e}-7$ & $9.0 \mathrm{e}-7$ & $9.6 e-7$ & $9.8 \mathrm{e}-4$ & $\begin{array}{l}\mathrm{cm}^{3} \text { gas / } \\
\mathrm{cm}^{3} \text { total }\end{array}$ \\
\hline$\theta_{\ell}(\mathrm{s})$ & 0.110 & 0.120 & 0.136 & 0.145 & 0.579 & $\begin{array}{l}\mathrm{cm}^{3} \text { liquid / } \\
\mathrm{cm}^{3} \text { total }\end{array}$ \\
\hline$A(\mathrm{t})$ & 0.0090 & 0.0077 & 0.0124 & 0.0138 & 0.21 & $\mathrm{~cm} / \sqrt{\mathrm{yr}}$ \\
\hline Nominal value & $N V$ & $N V$ & $N V$ & $N V$ & $N V$ & \\
\hline$S_{g}(\mathrm{u})$ & 0.02 & 0.02 & 0.02 & 0.02 & 0.02 & $\begin{array}{l}\mathrm{cm}^{3} \text { gas / } \\
\mathrm{cm}^{3} \text { void }\end{array}$ \\
\hline$S_{\ell}(\mathrm{q})$ & 0.98 & 0.98 & 0.98 & 0.98 & 0.98 & $\begin{array}{l}\mathrm{cm}^{3} \text { liquid / } \\
\mathrm{cm}^{3} \text { void }\end{array}$ \\
\hline$\theta_{g}(\mathrm{r})$ & 0.0022 & 0.0024 & 0.0027 & 0.0029 & 0.0116 & $\begin{array}{l}\mathrm{cm}^{3} \text { gas / } \\
\mathrm{cm}^{3} \text { total }\end{array}$ \\
\hline$\theta_{\ell}(\mathrm{s})$ & 0.108 & 0.118 & 0.133 & 0.142 & 0.568 & $\begin{array}{l}\mathrm{cm}^{3} \text { liquid / } \\
\mathrm{cm}^{3} \text { total }\end{array}$ \\
\hline
\end{tabular}


SRNL-STI-2013-00118, REVISION 0

\begin{tabular}{|r|c|c|c|c|c|l|}
\hline Parameter & SDU 2 & SDU 1/4 & $\begin{array}{c}\text { SDU 4 } \\
\text { Roof }\end{array}$ & $\begin{array}{c}\text { SDU 1 } \\
\text { Roof }\end{array}$ & Saltstone & Units \\
\hline$A(\mathrm{t})$ & 0.17 & 0.18 & 0.21 & 0.24 & 0.72 & $\mathrm{~cm} / \sqrt{\mathrm{yr}}$ \\
\hline $\begin{array}{l}\text { Conservative } \\
\text { estimate }\end{array}$ & $C E$ & $C E$ & $C E$ & $C E$ & $C E$ & \\
\hline$S_{g}(\mathrm{u})$ & 0.05 & 0.05 & 0.05 & 0.05 & 0.05 & $\begin{array}{l}\mathrm{cm}^{3} \text { gas / } \\
\mathrm{cm}^{3} \text { void }\end{array}$ \\
\hline$S_{\ell}(\mathrm{q})$ & 0.95 & 0.95 & 0.95 & 0.95 & 0.95 & $\begin{array}{l}\mathrm{cm}^{3} \text { liquid } / \\
\mathrm{cm}^{3} \text { void }\end{array}$ \\
\hline$\theta_{g}(\mathrm{r})$ & 0.0055 & 0.0060 & 0.0068 & 0.0073 & 0.0290 & $\begin{array}{l}\mathrm{cm}^{3} \text { gas } / \\
\mathrm{cm}^{3} \text { total }\end{array}$ \\
\hline$\theta_{\ell}(\mathrm{s})$ & 0.105 & 0.114 & 0.129 & 0.138 & 0.551 & $\begin{array}{l}\mathrm{cm}^{3} \text { liquid } / \\
\mathrm{cm}^{3} \text { total }\end{array}$ \\
\hline$A(\mathrm{t})$ & 0.27 & 0.28 & 0.33 & 0.37 & 1.14 & $\mathrm{~cm}^{/} \sqrt{\mathrm{yr}}$ \\
\hline
\end{tabular}

Table 3-1 notes:

(a) Millings (2012)

(b) $\mathrm{p}_{\mathrm{CO}_{2}}$ and ideal gas law at $20^{\circ} \mathrm{C}$

(c) $p_{\mathrm{CO}_{2}}$ and Henry's law w/ $k_{\mathrm{H}}=29.41 \mathrm{~L} \cdot \mathrm{atm} / \mathrm{mol}$ (http://en.wikipedia.org/wiki/Henry's law)

(d) SRR (2009), Table 4.2-16

(e) Marrero and Mason (1972), Table 20, $\mathrm{N}_{2}-\mathrm{CO}_{2}$ system

(f) SIMCO (2012), Tables 9 and 13, 28 day cure

(g) SIMCO (2010), Tables 6 and 13, WS-2 grout

(h) $D_{e, g}=\tau D_{m, g}$

(i) Langton (2010b) Table 1-1, based on SIMCO (2010), rounded to one significant figure

(j) $M_{\mathrm{Ca}(\mathrm{OH})_{2}}=40+2(16+1) \mathrm{g} / \mathrm{mol}$

(k) $c_{\mathrm{Ca}(\mathrm{OH})_{2}}=\left[\mathrm{Ca}(\mathrm{OH})_{2}\right] \rho_{b} / M_{\mathrm{Ca}(\mathrm{OH})_{2}}$

(l) The stoichiometry of CSH in cement paste is variable. SIMCO assumes

$\mathrm{CSH} \rightarrow 0.65 \mathrm{Ca}(\mathrm{OH})_{2}+\mathrm{CaH}_{2} \mathrm{SiO}_{4}=1.65 \mathrm{CaO} \cdot \mathrm{SiO}_{2} \cdot 1.65 \mathrm{H}_{2} \mathrm{O}$ in STADIUM

modeling (Samson 2010, Table 7). $M_{C S H}=1.65(40)+3.3(1)+1(28)+5.3(16) \mathrm{g} / \mathrm{mol}$

(m) $c_{C S H}=[\mathrm{CSH}] \rho_{b} / M_{C S H}$

(n) $c_{\mathrm{Ca}}=c_{\mathrm{Ca}(\mathrm{OH})_{2}}+1.65 \cdot c_{\mathrm{CSH}}$; see note (l)

(o) scaled from "SDU $1 / 4$ " concrete using $\mathrm{CaO}$ ratio from Table 3-2

(p) computed from van Genuchten (1980) water retention curve and $1500 \mathrm{~cm}$ suction

(q) $S_{g}+S_{\ell}=1$

(r) $\theta_{g}=S_{g} n$

(s) $\theta_{\ell}=S_{\ell} n$

(t) Equation (3.3)

(u) postulated condition. 
SRNL-STI-2013-00118, REVISION 0

Table 3-2. Estimated calcium content in SDU 1 and 4 roof concrete relative to SDU 1/4 floor concrete.

\begin{tabular}{|l|c|c|c|c|}
\hline \multicolumn{1}{|c|}{ Binder } & $\begin{array}{c}\mathrm{CaO} \\
(\%)\end{array}$ & $\begin{array}{c}\text { SDU 1/4 Floor } \\
\left(\mathrm{lbs} / \mathrm{yd}^{3}\right)\end{array}$ & $\begin{array}{c}\text { SDU 4 Roof } \\
\left({\left.\mathrm{lbs} / \mathrm{yd}^{3}\right)}^{3}\right.\end{array}$ & $\begin{array}{c}\text { SDU 1 Roof } \\
\left({\left.\mathrm{lbs} / \mathrm{yd}^{3}\right)}^{3}\right.\end{array}$ \\
\hline Type I/II cement Lafarge & 64.8 & 419 & 466 & 400 \\
\hline Type IV cement Lehigh & 63.8 & 0 & 0 & 0 \\
\hline GGBFS Holcim & 37.8 & 278 & 0 & 0 \\
\hline Force 10000 SF Grace & 0.6 & 0 & 0 & 0 \\
\hline Class F Fly Ash SEFA & 1.32 & 0 & 62 & 70 \\
\hline $\mathrm{CaO}_{\text {roof }} / \mathrm{CaO}_{\text {floor }}$ & - & - & 0.80 & 0.69 \\
\hline
\end{tabular}

The molar concentrations of $\mathrm{CO}_{2}$ in the gas and liquid phases are observed to be similar, whereas the effective diffusion coefficient for gas phase transport is 4 to 5 orders of magnitude larger than its counterpart for the liquid phase. Therefore gas phase transport generally controls the carbonation process, and liquid phase transport is commonly neglected in the literature (e.g. Papadakis et al. 1989). The exception is saturated conditions, where liquid phase transport is the only mechanism delivering $\mathrm{CO}_{2}$ to the reaction front. The carbonation rate is minimal under these conditions. As a specific example, Rast and Rinker (2012) reported a carbonation depth of 1-2 mm for a concrete core taken from a 50 year old Hanford waste tank. The rate of carbonation is also minimal under dry conditions, because water is required to support the aqueous reaction $\mathrm{Ca}(\mathrm{OH})_{2}+\mathrm{H}_{2} \mathrm{O}+\mathrm{CO}_{2} \rightarrow \mathrm{CaCO}_{3}+2 \mathrm{H}_{2} \mathrm{O}$. The maximum rate of carbonation occurs at intermediate conditions, roughly 50\% relative humidity (e.g. Papadakis et al. 1989, Walton et al. 1990). The carbonation rate is very sensitive to liquid saturation near full saturation.

Relative humidity and saturation are related through thermodynamic relationships and a material specific water retention curve. Total suction is related to water vapor pressure through the equilibrium thermodynamic relationship (Richards 1965, cited in Fredlund and Rahardjo 1993, Equations 4.1 and 4.3)

$$
\psi=\left(P_{g}-P_{\ell}\right) / \rho g+\pi=\psi_{c}+\pi=-\frac{R T}{g M_{w}} \ln \left(\frac{P_{v}}{P_{0}}\right)=-\frac{R T}{g M_{w}} \ln (R H)
$$

known as the Kelvin relationship where

$$
\begin{aligned}
& \psi=\text { total suction }[\mathrm{m}] \\
& P_{g}=\text { gas pressure }[\mathrm{Pa}] \\
& P_{\ell}=\text { liquid pressure }[\mathrm{Pa}] \\
& \rho=\operatorname{liquid} \text { density }\left[\mathrm{kg} / \mathrm{m}^{3}\right] \\
& g=\text { gravitational acceleration }\left[\mathrm{m} / \mathrm{s}^{2}\right] \\
& \pi=\text { osmotic suction }[\mathrm{m}]
\end{aligned}
$$




$$
\begin{aligned}
& \psi_{c}=\text { capillary or matric suction }[\mathrm{m}] \\
& R=\text { universal (molar) gas constant }\left[\mathrm{J} / \mathrm{mol}-\mathrm{K}=\mathrm{m}^{3} \mathrm{~Pa} / \mathrm{mol}-\mathrm{K}\right] \\
& T=\text { temperature }[\mathrm{K}] \\
& M_{w}=\text { molar mass of water }[\mathrm{kg} / \mathrm{mol}] \\
& P_{v}=\text { water vapor pressure }[\mathrm{Pa}] \\
& P_{0}=\text { vapor pressure at saturation }[\mathrm{Pa}] \\
& R H=\text { relative humidity, } P_{v} / P_{0}[-]
\end{aligned}
$$

In light of this expression, water vapor pressure can be viewed as a master variable defining the pressure state of both the gas and liquid phases (Hall and Hoff 2002). The osmotic suction can be estimated from the Morse equation (http://en.wikipedia.org/wiki/Osmotic_pressure)

$$
\rho g \pi=i M R T
$$

where

$$
\begin{aligned}
\rho & =\text { liquid density }\left[\mathrm{kg} / \mathrm{m}^{3}\right] \\
g & =\text { gravitational acceleration }\left[\mathrm{m} / \mathrm{s}^{2}\right] \\
\pi & =\text { osmotic suction }[\mathrm{m}] \\
i & =\text { van't Hoff factor }[-] \\
M & =\text { molarity of the solution }\left[\mathrm{mol} / \mathrm{m}^{3}\right] \\
R & =\text { universal (molar) gas constant }\left[\mathrm{J} / \mathrm{mol}-\mathrm{K}=\mathrm{m}^{3} \mathrm{~Pa} / \mathrm{mol}-\mathrm{K}\right] \\
T & =\text { temperature }[\mathrm{K}] .
\end{aligned}
$$

Equation (3.6) assumes a dilute solution, but can be used with increasing approximation for more concentrated solutions. The dimensionless van't Hoff factor is approximately one (http://en.wikipedia.org/wiki/Van_\%27t_Hoff_factor). Capillary suction is related to saturation through a water retention curve commonly expressed in the form (van Genuchten 1980)

$$
S_{e}=\frac{S-S_{r}}{1-S_{r}}=\frac{\theta-\theta_{r}}{\theta_{S}-\theta_{r}}=\left[\frac{1}{1+\left(\alpha \psi_{c}\right)^{n}}\right]^{m}
$$

where

$$
S=\text { saturation }\left[\mathrm{m}^{3} \text { liquid } / \mathrm{m}^{3} \text { void }\right]
$$




$$
\begin{aligned}
& S_{r}=\text { material specific fitting parameter }\left[\mathrm{m}^{3} \text { liquid } / \mathrm{m}^{3} \text { void }\right] \\
& \theta=\text { water content }\left[\mathrm{m}^{3} \text { liquid } / \mathrm{m}^{3} \text { total }\right] \\
& \theta_{r}=\text { material specific fitting parameters }\left[\mathrm{m}^{3} \text { liquid } / \mathrm{m}^{3} \text { total }\right] \\
& \theta_{s}=\text { saturated water content = porosity }\left[\mathrm{m}^{3} \text { liquid } / \mathrm{m}^{3} \text { total }\right] \\
& \alpha=\text { material specific fitting parameter }[1 / \mathrm{m}] \\
& \psi_{c}=\text { capillary or matric suction }[\mathrm{m}] \\
& n, m=\text { material specific fitting parameters }[-]
\end{aligned}
$$

and the subscripts $e$ and $r$ denote "effective" and "residual". Note that $S_{r}$ and $\theta_{r}$ are correlated (not independent) parameters. It is commonly assumed that $m=1-1 / n$. Figure 3-1 illustrates water retention curves characteristic of SDU concrete and saltstone (Phifer et al. 2006, Dixon 2011).

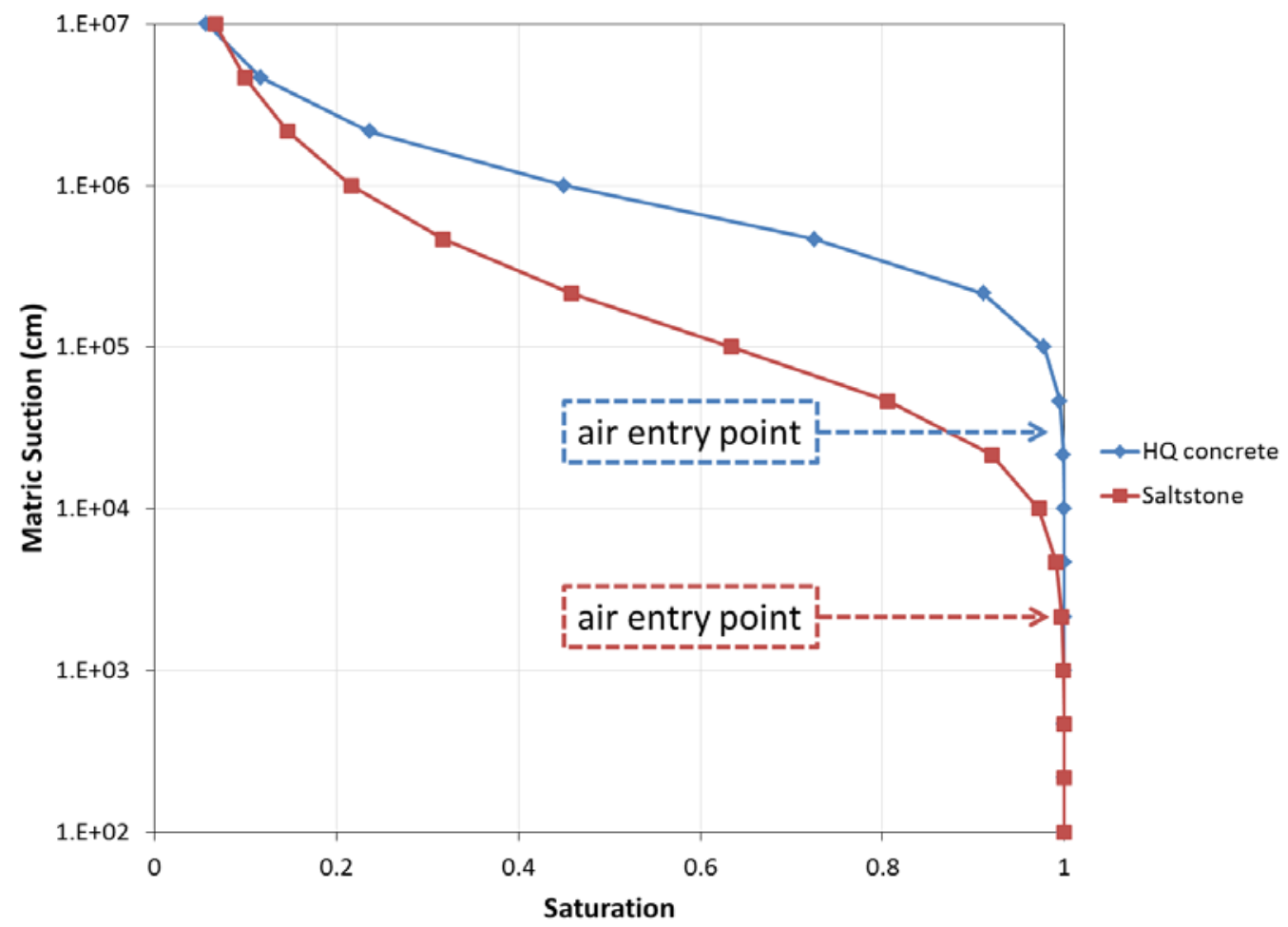

Figure 3-1. Water retention curves for SDF concrete and saltstone.

As mentioned previously, the saturation state of a cementitious material strongly affects the rate of carbonation, particularly in the vicinity of full saturation. The anticipated saturation states for SDF cementitious materials can be assessed using Equations (3.5) through (3.7) and estimated soil suction and relative humidity values. 
Once buried under a low-permeability cover system, the SDF will initially be exposed to soil conditions approaching gravity equilibrium (no infiltration), where the matric suction head is equal to height above the water table. Soil moisture contains dissolved solids, but the concentrations are dilute such that osmotic suction is negligible compared to that within cementitious materials. Any infiltration above zero produces lower capillary suction levels than gravity equilibrium. Thus as the cover system degrades over time, soil suction levels will decrease. With this consideration, the maximum suction head anticipated for SDUs is roughly $1500 \mathrm{~cm}$, the approximate height of the SDUs above the water table (15 meters). From Figure 3-1 the air entry head is observed to exceed 1000 $\mathrm{cm}$ for SDF grout and $10,000 \mathrm{~cm}$ for SDF concrete. Thus SDF concrete is expected to be saturated for all time. Ignoring osmotic effects, saltstone would be slightly unsaturated immediately after cap placement, and then become saturated when the soil suction levels fall below approximately $1000 \mathrm{~cm}$. Table 3-3 shows saturation calculated from the water retention curves depicted in Figure 3-1 for the expected maximum capillary suction of approximately $1500 \mathrm{~cm}$, and 10x higher and lower levels as points of reference.

Table 3-3. Saltstone and concrete saturation for selected capillary suctions.

\begin{tabular}{|r|rrr|rrr|r|}
\hline Parameter & Saltstone & & Concrete & & & Units \\
\hline saturated water content, $\theta_{\mathrm{s}}$ & 0.58 & 0.58 & 0.58 & 0.1 & 0.1 & 0.1 & \\
residual water content, $\theta_{\mathrm{r}}$ & 0 & 0 & 0 & 0 & 0 & 0 & \\
\hline van Genuchten $(1980) \alpha$ & $1.999 \mathrm{E}-05$ & $1.999 \mathrm{E}-05$ & $1.999 \mathrm{E}-05$ & $2.086 \mathrm{E}-06$ & $2.086 \mathrm{E}-06$ & $2.086 \mathrm{E}-06$ & $1 / \mathrm{cm}$ \\
\hline van Genuchten $(1980) \mathrm{n}$ & 1.51012 & 1.51012 & 1.51012 & 1.9433 & 1.9433 & 1.9433 & \\
\hline $\mathrm{m}=1-1 / \mathrm{n}$ & 0.338 & 0.338 & 0.338 & 0.485 & 0.485 & 0.485 & \\
\hline capillary suction, $\Psi_{\mathrm{c}}$ & 15000 & 1500 & 150 & 15000 & 1500 & 150 & $\mathrm{~cm}$ \\
\hline saturation & 0.950 & 0.998 & 1.000 & 0.999 & 1.000 & 1.000 & \\
\hline
\end{tabular}

The chemical compositions of pore water in SDU concrete and saltstone have been characterized by SIMCO (2010, 2012) and are reproduced in Table 3-4 through Table 3-6. The osmotic suctions associated with these molar concentrations are shown in Table 3-7 based on Equation (3.6). Over time dissolved species will advect and/or diffuse out of cementitious materials, thus lowering the initial molar concentrations, to levels approaching zero with sufficient time. Table 3-7 includes calculations for two additional concentrations: half the initial values and zero. The total suction is assumed to be 1500 $\mathrm{cm}$ in all cases based on the exposure to soil conditions. The relative humidity corresponding to $1500 \mathrm{~cm}$ is $99.89 \%$ from Equation (3.5). In comparison, carbonation rates reported in the literature are typically focused on $50-70 \%$ relative humidity, which is reflective of atmospheric exposure conditions and maximum penetration. For the initial and intermediate molar concentrations, the osmotic suctions exceed the total suction and the capillary suctions are negative-valued (Equation (3.5), total suction is composed of capillary and osmotic suction). The latter implies the pore water pressure is positive, in contrast to pure water that is under tension (negative pressure). Therefore, saturation is $100 \%$ when dissolved species are present at these concentrations. 
Table 3-4. Pore fluid composition for SDU 2 concrete (SIMCO 2012, Table 11).

\begin{tabular}{|c|c|c|c|c|c|}
\hline & 28d V2 & MW & 28d V2 & 28d V2 & water \\
\hline ion & $\mathrm{mmol} / \mathrm{L}$ & $\mathrm{g} / \mathrm{mol}$ & $\mathrm{mol} / \mathrm{L}$ & g/L & g/L \\
\hline $\mathrm{OH}^{-}$ & 113.9 & 17 & 0.114 & 1.94 & \\
\hline $\mathrm{Na}^{+}$ & 26.5 & 23 & 0.027 & 0.61 & \\
\hline $\mathrm{K}^{+}$ & 35.8 & 39 & 0.036 & 1.40 & \\
\hline $\mathrm{SO}_{4}{ }^{2-}$ & 0 & 96 & 0.000 & 0.00 & \\
\hline $\mathrm{Ca}^{2+}$ & 2 & 40 & 0.002 & 0.08 & \\
\hline $\mathrm{Cl}^{-}$ & 4.2 & 35 & 0.004 & 0.15 & \\
\hline $\mathrm{N} \dagger$ & & & 0.000 & 0.00 & \\
\hline \multirow[t]{3}{*}{$\mathrm{CO}_{3}{ }^{2-}$} & & & 0.000 & 0.00 & \\
\hline & & & 0.182 & 4.2 & 998 \\
\hline & & & & $0.4 \%$ & \\
\hline
\end{tabular}

Table 3-5. Pore fluid composition for SDU 1/4 concrete (SIMCO 2012, Table 11).

\begin{tabular}{|c|r|r|r|r|r|r|}
\hline & $28 d$ V4 & MW & 28d V4 & 28d V4 water \\
\hline ion & mmol/L & g/mol & mol/L & g/L & g/L \\
\hline $\mathrm{OH}^{-}$ & 244.4 & 17 & 0.244 & 4.15 & \\
\hline $\mathrm{Na}^{+}$ & 73.9 & 23 & 0.074 & 1.70 & \\
\hline $\mathrm{K}^{+}$ & 140.7 & 39 & 0.141 & 5.49 & \\
\hline $\mathbf{S O}_{4}{ }^{2-}$ & 0.1 & 96 & 0.000 & 0.01 & \\
\hline $\mathbf{C a}^{2+}$ & 1.8 & 40 & 0.002 & 0.07 & \\
\hline $\mathbf{C l}^{-2}$ & 4.8 & 35 & 0.005 & 0.17 & \\
\hline $\mathbf{N}^{+}$ & & & 0.000 & 0.00 & \\
\hline $\mathbf{C O}_{3}{ }^{2-}$ & & & 0.000 & 0.00 & \\
\hline & & & $\mathbf{0 . 4 6 6}$ & 11.6 & 998 \\
\hline & & & & & $1.1 \%$ & \\
\hline
\end{tabular}

Table 3-6. Pore fluid composition for saltstone (SIMCO 2010, Table 8).

\begin{tabular}{|c|c|c|c|c|c|}
\hline & 28d saltstone & 28d saltstone & 28d saltstone & 28d saltstone & water \\
\hline ion & $\mathrm{mmol} / \mathrm{L}$ & $\mathrm{mg} / \mathrm{L}$ & $\mathrm{mol} / \mathrm{L}$ & g/L & g/L \\
\hline $\mathrm{OH}^{-}$ & 383.9 & 6528 & 0.384 & 6.53 & \\
\hline $\mathrm{Na}^{+}$ & 4144.2 & 95274 & 4.144 & 95.27 & \\
\hline $\mathrm{K}^{+}$ & 120.5 & 4712 & 0.121 & 4.71 & \\
\hline $\mathrm{SO}_{4}{ }^{2-}$ & 111.7 & 10731 & 0.112 & 10.73 & \\
\hline $\mathrm{Ca}^{2+}$ & 0.1 & 2 & 0.000 & 0.00 & \\
\hline $\mathrm{Cl}^{-}$ & 11.9 & 421 & 0.012 & 0.42 & \\
\hline $\mathbf{N} \dagger$ & 3552.1 & 214540 & 3.552 & 214.54 & \\
\hline \multirow[t]{3}{*}{$\mathrm{CO}_{3}{ }^{2-}$} & 46.8 & 4683 & 0.047 & 4.68 & \\
\hline & & & 8.371 & 336.9 & 998 \\
\hline & & & & $25 \%$ & \\
\hline
\end{tabular}


Table 3-7. Relative humidity and capillary suction corresponding to a total suction of $1500 \mathrm{~cm}$.

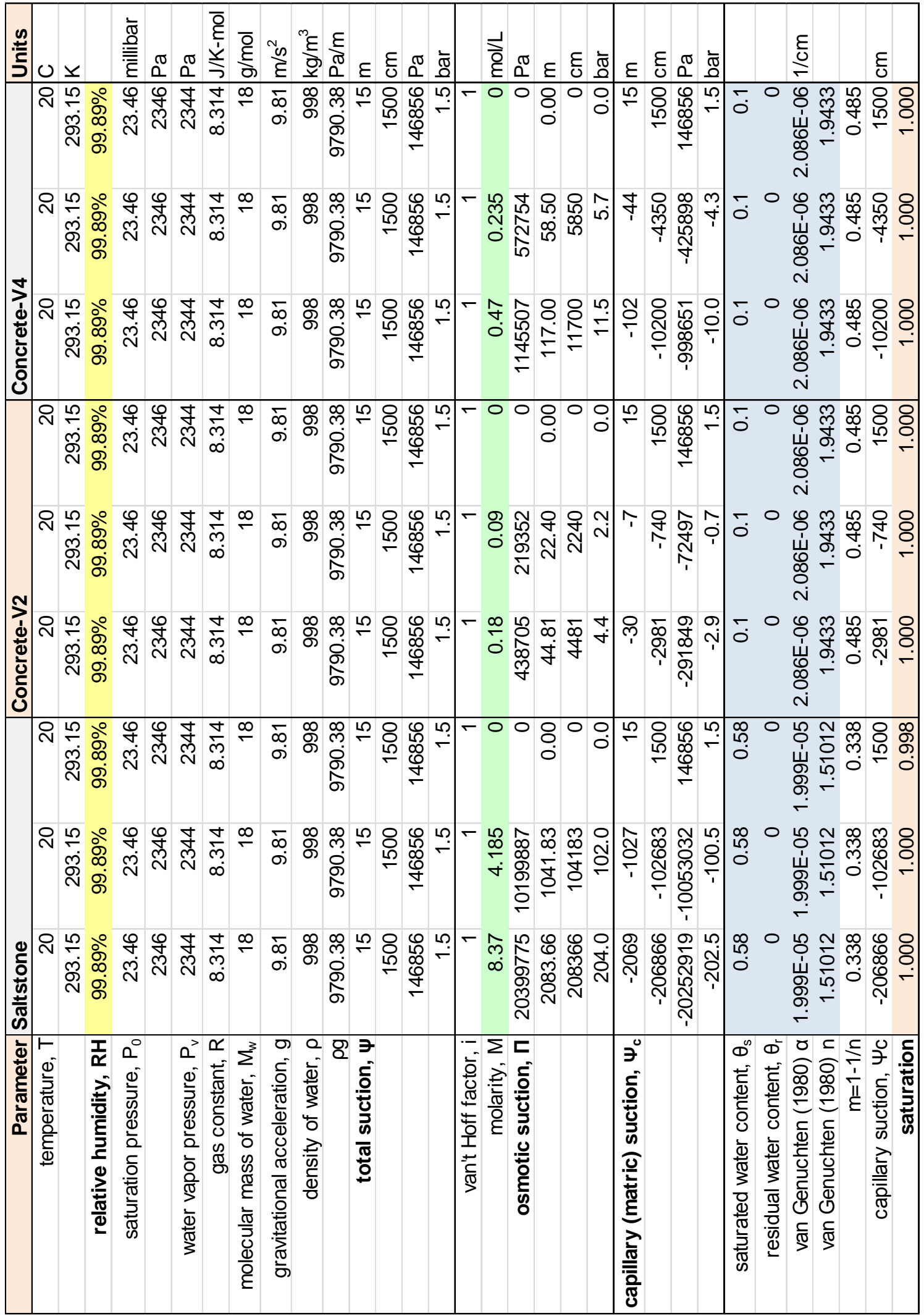


The practical implication is that saltstone is expected to be fully saturated at early times, when soil suction levels are the highest, because of osmotic suction. At later times when the molar concentration of the pore fluid drops, soil (total) suction levels will also be lower such that saltstone will remain saturated, even with pure water in its pore space. Thus the pore spaces of both concrete and grout are expected to be fully saturated for all time once these materials are in the subsurface.

While saturated pores preclude gas-phase $\mathrm{CO}_{2}$ transport and relatively fast carbonation, these processes may occur should either cementitious material be fractured, depending on matric suction levels and crack aperture. For a perfectly wetting fluid, the capillary rise between two vertical parallel surfaces is

$$
h=\frac{2 \sigma}{\rho g b}
$$

where

$$
\begin{aligned}
h & =\text { capillary rise }[\mathrm{m}] \\
\sigma & =\text { surface tension }[\mathrm{N} / \mathrm{m}] \\
\rho & =\operatorname{density}\left[\mathrm{kg} / \mathrm{m}^{3}\right] \\
g & =\text { gravitation acceleration }\left[\mathrm{m} / \mathrm{s}^{2}\right] \\
b & =\text { aperture }[\mathrm{m}]
\end{aligned}
$$

In the context of a vertical fracture subjected to a given pressure head, $P / \rho g[\mathrm{~m}]$, in the surrounding matrix, the aperture will be liquid-filled under the condition (Wang and Narasimhan 1985)

$$
\frac{P}{\rho g}>-\frac{2 \sigma}{\rho g b}
$$

In other words, the fracture will be liquid-filled for positive pressure head and suction (negative pressure) head less than $2 \sigma / \rho g b$. Alternatively, the maximum aperture that can be liquid-filled for a given capillary suction head, $\psi_{c}[\mathrm{~m}]$, is

$$
b=\frac{2 \sigma}{\rho g \psi_{c}}
$$

For $\psi_{c}=1500 \mathrm{~cm}=15 \mathrm{~m}$, the result is $\mathrm{b}=1 \mu \mathrm{m}=0.04$ mil. Hence fractures, if present, are expected to be unsaturated unless very narrow. If these postulated fractures are connected, then they would provide a means for gas-phase transport of $\mathrm{CO}_{2}$ through the porous medium.

Returning to Equations (3.2) and (3.3), three conditions are considered for predicting carbonation rates in SDU concrete and saltstone, as shown in Table 3-1. The bestestimate $(\mathrm{BE})$ rate is calculated assuming a capillary suction of $1500 \mathrm{~cm}$ and pure water 
occupying pore space, i.e., neglecting osmotic effects. Under these conditions SDF concrete is fully liquid saturated and SDF grout is liquid saturated at $99.8 \%$. The "bestestimate (BE)" label is somewhat of a misnomer because suction levels will be less than $1500 \mathrm{~cm}$ for much of the performance period, osmotic effects are present, and saltstone is expected to be liquid saturated. Rather, the label is used in a relative sense compared to the other two scenarios. The conservative-estimate (CE) rate implicitly assumes that connected fractures or similar unsaturated macro-porous features are present such that an equivalent of $5 \%$ of the pore space is open for gas-phase transport, i.e., $5 \%$ gas saturation. An intermediate setting of $2 \%$ gas saturation is chosen for the nominal value (NV) calculation. Table 3-1 indicates the carbonation rate coefficient $A[\mathrm{~cm} / \sqrt{ } \mathrm{yr}]$ from Equation (3.3) for the BE, NV, and CE conditions. The carbonation rate coefficient can be used in Equation (1.8) to predict failure time $t_{0}$ for a specified material thickness $x_{0}$.

As a point of reference, Brown et al. (2012) performed detailed simulations of carbonation in "VCT" concrete, which is essentially Saltstone SDU 2 concrete, using LeachXSTM/ORCHESTRA in a developmental CBP Software Toolbox carbonation module (Brown et al. 2013a, b). The carbonation depth was defined as the location where $\mathrm{pH}<9$. Figure 3-2 is a reproduction of simulation results for various $\mathrm{CO}_{2}$ concentrations based on 30\% porosity, 90\% liquid saturation, and a diffusion coefficient of $1 . \mathrm{E}-6 \mathrm{~m} / \mathrm{s}$. These settings are more conservative than any of the cases considered in Table 3-1. Focusing on the $1 \% \mathrm{CO}_{2}$ curve (0.01 atm), the numerical simulations are observed to exhibit an initial time lag before the carbonation front advances from the exposure surface. After $\mathrm{Vt}=15 \mathrm{Vyr}(\mathrm{t}=225 \mathrm{yr})$, the carbonation front stalls at about $1.25 \mathrm{~cm}$. Using $t_{0}=225 \mathrm{yr}$ and $x_{0}=1.25 \mathrm{~cm}$ in Equation (1.7), the equivalent carbonation rate constant is $A=0.083 \mathrm{~cm} / \sqrt{ }$ yr. The latter is significantly lower than the conservativeestimate value in Table 3-1, which suggests that the analytic solution given by Equation (3.2) and other input assumptions are biased in the conservative direction.

Implicit in Equations (1.2) and (3.2) is the assumption of a constant diffusion coefficient. If physical damage is occurring as a result of carbonation, then the diffusion coefficient may increase and the front penetrate deeper than indicated by a $V_{t}$ dependence. The $V_{t}$ dependence is a result of increasing distance between the exposure boundary and reaction front. If damage occurs around the reaction front, then the diffusion distance may effectively not increase beyond some maximum distance, $\delta[\mathrm{cm}]$, and penetration will be proportional to time instead of $\sqrt{ } \mathrm{t}$. Assuming penetration initially follows Equation (1.5), this alternative relationship is described by

$$
x=\frac{\delta}{t_{\delta}} t=\frac{\delta}{\delta^{2} / A^{2}} t=\frac{A^{2}}{\delta} t
$$

where

$\delta=$ penetration through time $t_{\delta}[\mathrm{cm}]$

$t_{\delta}=$ time at which penetration reaches $\delta$ [yr] 
Equations (1.5) and (3.11) are schematically depicted in Figure 3-3. Solving Equation (3.11) for time yields

$$
t=\frac{\delta x}{A^{2}}
$$

compared to

$$
t=\frac{x^{2}}{A^{2}}
$$

for a fixed diffusion coefficient from Equation (1.5). To account for the feedback effects of physical damage on diffusion rates, the minimum of Equations (3.12) and (3.13) is taken as the estimated failure time $t_{0}$ for a specified material thickness $x_{0}$ :

$$
t_{0}=\min \left[\frac{x_{0}^{2}}{A^{2}}, \frac{\delta x_{0}}{A^{2}}\right] \text {. }
$$

The minimum time curve is shown in Figure 3-3 as a dashed red line. A reasonable assumption for the maximum diffusion distance, $\delta$ [yr], is the depth of concrete cover over reinforcing steel, approximately $5 \mathrm{~cm}$ in typical construction based on American Concrete Institute (ACI) code 318 (http://en.wikipedia.org/wiki/Concrete_cover). Calculation of specific failure times is postponed until Section 5.0.

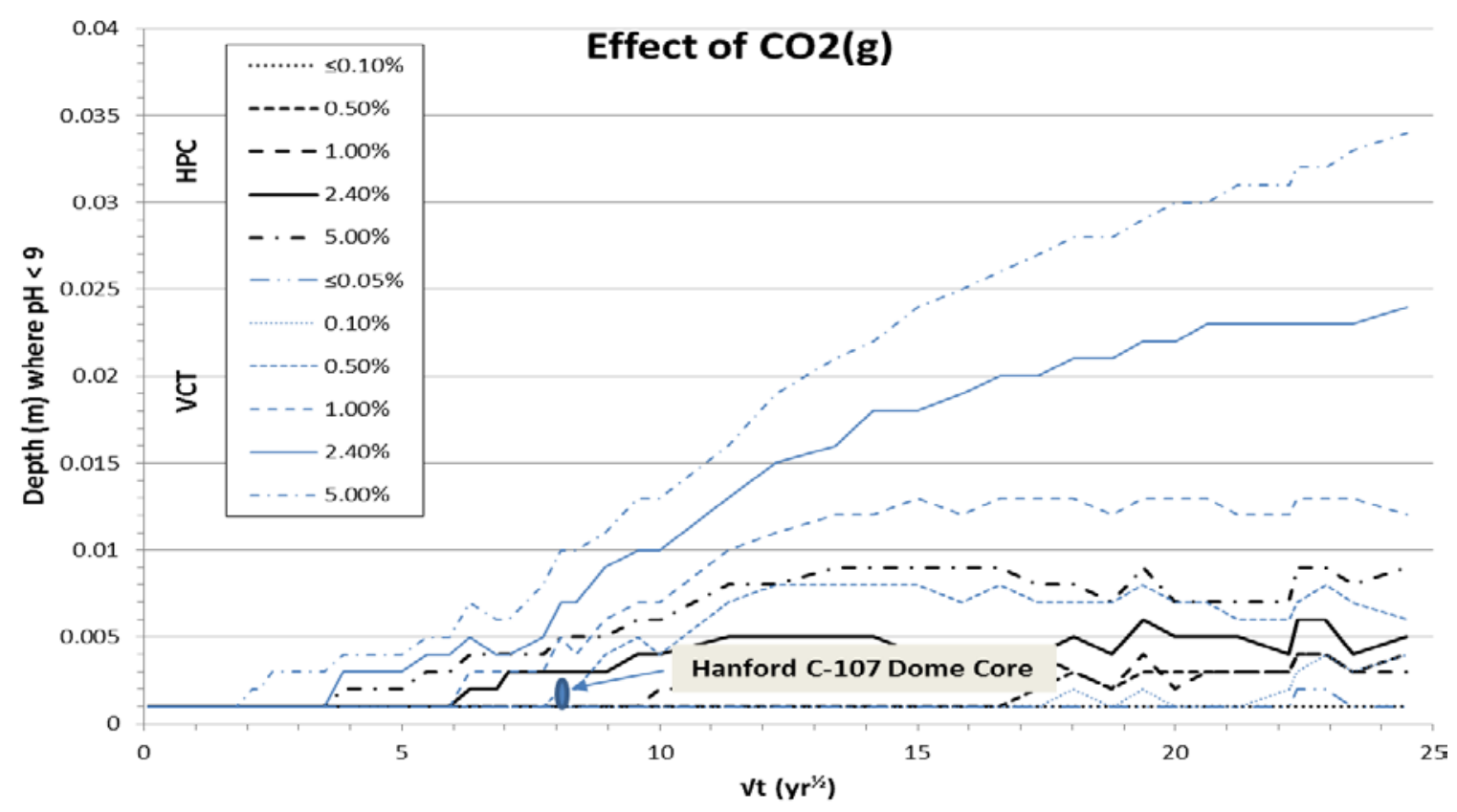

Figure 3-2. Carbonation simulation results as a function of soil-gas $\mathrm{CO}_{2}$ concentration for $90 \%$ concrete saturation from Brown et al (2012) (VCT = SDU 2 concrete, HPC = high performance concrete). 


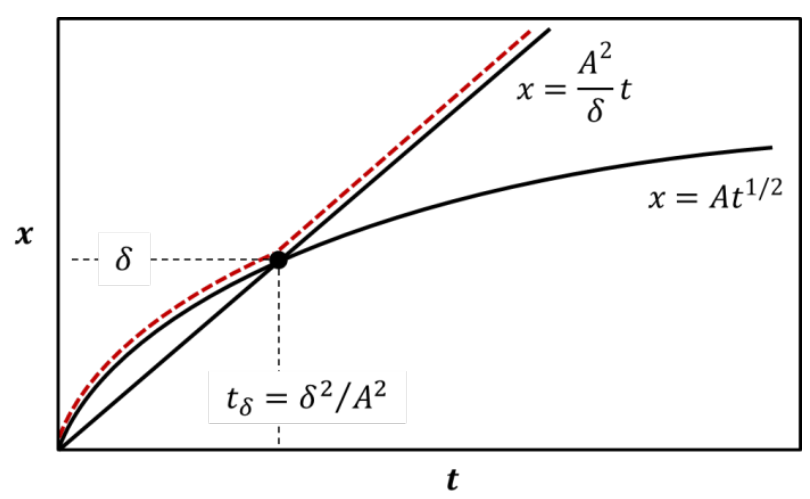

Figure 3-3. Square-root and linear penetration with respect to time.

\subsection{DECALCIFICATION}

Decalcification in this application refers to leaching of $C a^{2+}$ in pore water to exterior soil, where the concentration is assumed to be zero (Walton et al. 1990, Langton 2007, 2010a). Leaching may occur through diffusion and/or advection. For diffusion-controlled release between a sharp dissolution front and the soil interface, the penetration depth follows the general Equation (1.2) as

$$
x=\left[\frac{2 \theta D_{e} C_{C a^{2+}}}{{ }^{C} C a}\right]^{1 / 2}=A t^{1 / 2}
$$

where

$$
\begin{aligned}
& x=\text { penetration depth }[\mathrm{cm}] \\
& \theta=\text { liquid content, } \mathrm{Sn}\left[\mathrm{cm}^{3} \text { liquid } / \mathrm{cm}^{3} \text { total }\right] \\
& D_{e}=\text { effective diffusion coefficient for liquid phase, } \tau D_{m}\left[\mathrm{~cm}^{2} / \mathrm{yr}\right] \\
& t=\text { elapsed time }[\mathrm{yr}] \\
& c_{C a^{2+}}=\text { dissolved } \mathrm{Ca}^{2+} \text { concentration }\left[\mathrm{mol} / \mathrm{cm}^{3}\right. \text { liquid] } \\
& c_{C a}=\text { calcium concentration in solid phase }\left[\mathrm{mol} / \mathrm{cm}^{3} \text { total }\right]
\end{aligned}
$$

and

$$
A \equiv\left[\frac{2 \theta D_{e} c a^{2+}}{c_{C a}}\right]^{1 / 2}
$$

Table 4-1 summarizes best-estimate input parameters for use in Equations (4.1) and (4.2). Most parameters come from Table 3-1. The concentration of $\mathrm{Ca}^{2+}$ varies through the leaching process; alkali metals leach first, followed by $(\mathrm{OH})_{2}$, and then $\mathrm{CSH}$ (Walton et al. 1990). In this analysis dissolution of $C S H$ is assumed to control the concentration of 
$\mathrm{Ca}^{2+}$ over most of the leaching process, considering that little or no Portandite is expected in SDF cementitious materials (Table 4-1). CSH dissolves incongruently in that calcites leach preferentially in comparison to silicates. SIMCO (2012, Table 11) measured $c_{\mathrm{Ca}^{2+}}=1.8-2.0 \mathrm{mmol} / \mathrm{L}$ in SDU concrete, which is consistent with Clodic and Meike (1997, Table 15, Ca/Si = 0.9). A value of $2 . \mathrm{e}-6 \mathrm{~mol} / \mathrm{cm}^{3}$ is assumed in Table 4-1. The rate constants for decalcification controlled by diffusion are low indicating a slow process.

While diffusion may control the decalcification of thinner features at earlier times, specifically in concrete barriers, advection is more likely to control decalcification of saltstone considering its greater dimensions and high hydraulic conductivity. Considering downward flow, a quasi-steady state advective mass balance for decalcification is

$$
U \cdot c_{C a^{2+}} \cdot t=c_{C a} \cdot h
$$

where

$$
\begin{aligned}
U & =\text { Darcy velocity (volumetric water flux) }[\mathrm{cm} / \mathrm{yr}] \\
t & =\text { elapsed time }[\mathrm{yr}] \\
h & =\text { monolith height }[\mathrm{cm}]
\end{aligned}
$$

and the concentrations are as defined for Equation (4.1). Equation (4.3) assumes that advection occurs uniformly through the entire thickness, the dissolution front advances uniformly, and the exit concentration coincides with $\mathrm{Ca}^{2+}$ solubility. Solving for time yields

$$
t=\frac{c_{C a}}{c_{C a^{2+}}} \cdot \frac{h}{U} \equiv\left(\frac{1}{A_{U}}\right) \cdot h
$$

where $A_{U}[\mathrm{~cm} / \mathrm{yr}]$ is the rate coefficient for this advection-based degradation. Equation (4.4) is more limiting than Equation (4.1) for saltstone.

The hydraulic head gradient in vadose zone soil tends to be one or less, such that the flowrate is equal to or less than the saturated hydraulic conductivity, per Darcy's law. For a cementitious monolith placed in the vadose zone, the head gradient can be higher as infiltration flows around the lower permeability obstacle. The assumptions for the BE, $\mathrm{NV}$, and CE scenarios are $U=1,10$, and 100 times the saturated conductivity respectively.

The hydraulic conductivity of saltstone may vary with water to premix ratios and curing temperature profiles. An analysis of recent production runs (Isom 2012) indicates the water to premix ratio is bounded by a low value of 0.59 and a high value of 0.64 . Reigel et al. (2012) characterized the saturated conductivity of saltstone for various water to premix ratios and two different curing temperature profiles. The average hydraulic conductivity for this operating band is $6.4 \mathrm{E}-09 \mathrm{~cm} / \mathrm{s}$ (Table 4-2). Calculation of specific degradation times is postponed until Section 5.0. 
Table 4-1. Input data and rate constants for diffusion-limited decalcification.

\begin{tabular}{|c|c|c|c|c|c|c|}
\hline Parameter & SDU 2 & $\begin{array}{c}S D U \\
1 / 4\end{array}$ & $\begin{array}{c}\text { SDU } 4 \\
\text { Roof }\end{array}$ & $\begin{array}{l}\text { SDU } 1 \\
\text { Roof }\end{array}$ & Saltstone & Units \\
\hline$c_{C a^{2+}}(\mathrm{a})$ & $2.0 \mathrm{e}-6$ & 2.0e-6 & 2.0e-6 & $2.0 \mathrm{e}-6$ & $2.0 \mathrm{e}-6$ & $\mathrm{~mol} / \mathrm{cm}^{3}$ liquid \\
\hline$n(\mathrm{~b})$ & 0.11 & 0.12 & 0.136 & 0.145 & 0.58 & $\begin{array}{l}\mathrm{cm}^{3} \text { void } / \mathrm{cm}^{3} \\
\text { total }\end{array}$ \\
\hline$\rho_{b}(\mathrm{~b})$ & 2.22 & 2.24 & 2.21 & 2.20 & 1.01 & $\mathrm{~g} / \mathrm{cm}^{3}$ total \\
\hline$D_{e}(\mathrm{~b}, \mathrm{c})$ & $\begin{array}{l}5.0 \mathrm{e}-8 \\
\text { (b) }\end{array}$ & $\begin{array}{l}5.0 \mathrm{e}-8 \\
\text { (b) }\end{array}$ & $\begin{array}{l}1.0 \mathrm{e}-7 \\
\text { (b) }\end{array}$ & $\begin{array}{l}1.0 \mathrm{e}-7 \\
\text { (b) }\end{array}$ & $\begin{array}{l}1.0 \mathrm{e}-8 \\
\text { (c) }\end{array}$ & $\mathrm{cm}^{2} / \mathrm{s}$ \\
\hline $\begin{array}{r}{\left[\mathrm{Ca}(\mathrm{OH})_{2}\right]} \\
(\mathrm{d}, \mathrm{e})\end{array}$ & $\begin{array}{c}0 \\
(\mathrm{~d})\end{array}$ & $\begin{array}{l}7.2 \\
\text { (d) }\end{array}$ & - & - & $\begin{array}{c}0 \\
(\mathrm{e})\end{array}$ & $\mathrm{g} / \mathrm{kg}$ \\
\hline$M_{\mathrm{Ca}(\mathrm{OH})_{2}}(\mathrm{f})$ & 74 & 74 & - & - & 74 & $\mathrm{~g} / \mathrm{mol}$ \\
\hline$c_{\mathrm{Ca}(\mathrm{OH})_{2}}(\mathrm{~g})$ & 0 & $2.18 \mathrm{e}-4$ & - & - & 0 & $\mathrm{~mol} / \mathrm{cm}^{3}$ total \\
\hline$[C S H](\mathrm{d}, \mathrm{e})$ & $\begin{array}{l}81.2 \\
\text { (d) }\end{array}$ & $\begin{array}{c}118.8 \\
\text { (d) }\end{array}$ & - & - & $\begin{array}{c}147.4 \\
\text { (e) }\end{array}$ & $\mathrm{g} / \mathrm{kg}$ \\
\hline$M_{C S H}(\mathrm{~h})$ & 182.1 & 182.1 & - & - & 182.1 & $\mathrm{~g} / \mathrm{mol}$ \\
\hline$c_{C S H}(\mathrm{i})$ & $9.90 \mathrm{e}-4$ & $1.46 \mathrm{e}-3$ & - & - & $8.18 \mathrm{e}-4$ & $\mathrm{~mol} / \mathrm{cm}^{3}$ total \\
\hline$c_{C a}(\mathrm{j}, \mathrm{k})$ & $\begin{array}{c}1.63 e-3 \\
(j)\end{array}$ & $\begin{array}{c}2.63 e-3 \\
(j)\end{array}$ & $\begin{array}{c}2.11 \mathrm{e}-3 \\
(\mathrm{k})\end{array}$ & $\begin{array}{c}1.82 \mathrm{e}-3 \\
(\mathrm{k})\end{array}$ & $\begin{array}{c}1.35 e-3 \\
(j)\end{array}$ & $\mathrm{mol} / \mathrm{cm}^{3}$ total \\
\hline$S_{\ell}(\mathrm{l})$ & 1 & 1 & 1 & 1 & 0.9983 & $\begin{array}{l}\mathrm{cm}^{3} \text { liquid } / \mathrm{cm}^{3} \\
\text { void }\end{array}$ \\
\hline$\theta_{\ell}(\mathrm{m})$ & 0.110 & 0.120 & 0.136 & 0.145 & 0.579 & $\begin{array}{l}\mathrm{cm}^{3} \text { liquid } / \mathrm{cm}^{3} \\
\text { total }\end{array}$ \\
\hline$A(\mathrm{n})$ & 0.021 & 0.017 & 0.028 & 0.032 & 0.023 & $\mathrm{~cm} / \sqrt{\mathrm{yr}}$ \\
\hline
\end{tabular}

Table 4-1 notes:

(a) approximate solubility of $\mathrm{CSH}$

(b) SRR (2009), Table 4.2-16

(c) Langton (2010b) Table 1-1, based on SIMCO (2010), rounded to one significant figure

(d) SIMCO (2012), Tables 9 and 13, 28 day cure

(e) SIMCO (2010), Tables 6 and 13, WS-2 grout

(f) $M_{\mathrm{Ca}(\mathrm{OH})_{2}}=40+2(16+1) \mathrm{g} / \mathrm{mol}$

(g) $c_{\mathrm{Ca}(\mathrm{OH})_{2}}=\left[\mathrm{Ca}(\mathrm{OH})_{2}\right] \rho_{b} / M_{\mathrm{Ca}(\mathrm{OH})_{2}}$

(h) The stoichiometry of CSH in cement paste is variable. SIMCO assumes

$\mathrm{CSH} \rightarrow 0.65 \mathrm{Ca}(\mathrm{OH})_{2}+\mathrm{CaH}_{2} \mathrm{SiO}_{4}=1.65 \mathrm{CaO} \cdot \mathrm{SiO}_{2} \cdot 1.65 \mathrm{H}_{2} \mathrm{O}$ in STADIUM

modeling (Samson 2010, Table 7). $M_{C S H}=1.65(40)+3.3(1)+1(28)+5.3(16) \mathrm{g} / \mathrm{mol}$

(i) $c_{C S H}=[C S H] \rho_{b} / M_{C S H}$

(j) $c_{\mathrm{Ca}}=c_{\mathrm{Ca}(\mathrm{OH})_{2}}+1.65 \cdot c_{\mathrm{CSH}}$; see note (h)

(k) scaled from "SDU 1/4” concrete using CaO ratio from Table 3-2

(l) computed from van Genuchten (1980) water retention curve and $1500 \mathrm{~cm}$ suction

(m) $\theta_{\ell}=S_{\ell} n$

(n) Equation (4.2). 
Table 4-2. Measured hydraulic conductivity from SRNL-STI-2012-00558 (Reigel et al. 2012).

\begin{tabular}{|c|c|c|c|c|}
\hline \multirow{3}{*}{$\begin{array}{l}\text { Final } w / p \\
\quad \text { ratio }\end{array}$} & \multicolumn{4}{|c|}{ Hydraulic Conductivity (cm/s) } \\
\hline & \multicolumn{2}{|c|}{$\begin{array}{c}\text { Cell K Temperature } \\
\text { Profile } \\
\end{array}$} & \multicolumn{2}{|c|}{$\begin{array}{c}\text { Cell F Temperature } \\
\text { Profile } \\
\end{array}$} \\
\hline & Saturated & $\begin{array}{l}\text { Exposed } \\
\text { Surface }\end{array}$ & Saturated & $\begin{array}{c}\text { Exposed } \\
\text { Surface }\end{array}$ \\
\hline 0.59 & $1.7 \mathrm{E}-09$ & 4.5E-09 & $1.4 \mathrm{E}-09$ & 4.3E-09 \\
\hline 0.59 & $1.9 \mathrm{E}-09$ & $3.9 \mathrm{E}-10$ & $3.6 \mathrm{E}-09$ & $1.6 \mathrm{E}-09$ \\
\hline 0.6 & $1.7 \mathrm{E}-09$ & 1.7E-09 & 4.1E-09 & $2.1 \mathrm{E}-09$ \\
\hline 0.6 & $2.1 \mathrm{E}-09$ & $2.2 \mathrm{E}-09$ & 3.7E-09 & 1.3E-09 \\
\hline 0.64 & $3.2 \mathrm{E}-08$ & 4.5E-08 & 7.0E-09 & 1.3E-09 \\
\hline 0.64 & 9.6E-09 & 1.3E-08 & 5.0E-09 & $3.1 \mathrm{E}-09$ \\
\hline Maximum & $3.2 \mathrm{E}-08$ & 4.5E-08 & 7.0E-09 & 4.3E-09 \\
\hline Average & 8.2E-09 & $1.1 \mathrm{E}-08$ & $4.1 \mathrm{E}-09$ & 2.3E-09 \\
\hline Maximum & \multicolumn{2}{|c|}{$4.5 \mathrm{E}-08$} & \multicolumn{2}{|c|}{ 7.0E-09 } \\
\hline Average & \multicolumn{2}{|c|}{ 9.7E-09 } & \multicolumn{2}{|c|}{$3.2 \mathrm{E}-09$} \\
\hline Maximum & \multicolumn{4}{|c|}{ 4.5E-08 } \\
\hline Average & \multicolumn{4}{|c|}{ 6.4E-09 } \\
\hline
\end{tabular}

\subsection{SDF CEMENTITIOUIS MATERIAL DEGRADATION TIMES}

Degradation rates are defined for sulfate attack, carbonation-induced steel corrosion, and decalcification in Tables 5-1 through 5-3 at three levels: conservative estimate (CE), nominal value (NV), and best estimate (BE). As noted in the Introduction, the nominal value is defined to be an intermediate result that is more probable than the conservative estimate and more defensible than the best estimate. Tables 5-1 through 5-3 present the thicknesses of the key SDU cementitious components. Failure times can be computed from degradation rates and material thicknesses using Equation (2.3) for sulfate attack, Equation (3.14) for carbonation, and Equation (4.4) for decalcification.

Carbonation advances from the outside in, while sulfate attack, arising from sulfate in saltstone pore water, occurs from the inside moving outward. Failure is assumed to occur when the two reaction fronts meet. In some cases, one or the other degradation mechanism is delayed. Sulfate attack on the underside of each SDU roof is delayed until sulfate migrates through the clean grout overlying saltstone. SDU 2 has a High Density Polyethylene (HDPE) liner along the exterior of the walls and a composite layer of HDPE and a Geosynthetic Clay Liner (GCL) that covers the roof and separates the upper and lower mudmats. Carbonation in SDU 2 concrete is assumed to be delayed until HDPE/GCL liners are significantly degraded. If the delay is long enough for one process, the other may fully penetrate the thickness in question. 
The lag time for sulfate to reach the roof is estimated using the analytic solution for diffusion into a semi-infinite medium (Myer 1971, Equation (6.4.29); Flach et al. 2009, Equation 19b)

$$
c=c_{0} \operatorname{erfc}\left(\frac{x}{2 \sqrt{D_{e} t}}\right)
$$

where

$$
\begin{aligned}
& c=\text { interior concentration }[\mathrm{mol} / \mathrm{L}] \\
& c_{0}=\text { boundary concentration }[\mathrm{mol} / \mathrm{L}] \\
& x=\text { penetration depth }[\mathrm{cm}] \\
& D_{e}=\text { effective diffusion coefficient for liquid phase, } \tau D_{m}\left[\mathrm{~cm}^{2} / \mathrm{yr}\right] \\
& t=\text { elapsed time }[\mathrm{yr}]
\end{aligned}
$$

The penetration depth is the thickness of the clean grout. Effective diffusion coefficients are defined in Table 3-1 and Table 4-1 (same values). The ratio $c / c_{0}$ is assumed to be $10 \%, 20 \%$, and $50 \%$ for the CE, NV, and BE cases. When these trigger values are reached, carbonation is conservatively assumed to occur as though the underside of the roof were exposed to the full sulfate concentration, $c_{0}$. The resulting delay times are indicated in Table 5-1 through Table 5-3.

Significant degradation of the HDPE and GCL barriers is assumed to be necessary for $\mathrm{CO}_{2}$ diffusion into the concrete. The degradation of these barriers is evaluated in Flach et al. (2009) and data extracted from Appendix E of SRNL-STI-2009-00115 is provided in Table 5-4. "Significant" degradation is defined as a 100x increase in hydraulic conductivity (due to holes, tears), and occurs at approximately 900 and 1400 years for HDPE and HDPE-GCL respectively. These delay times appear in Table 5-1.

The maximum diffusion distance, $\delta$ [cm], in Equation (3.14) is generally assumed to be 5 $\mathrm{cm}$, the typical thickness of concrete cover over reinforcing steel based on ACI code 318, as previously discussed. The exception is the floor and upper mudmat system. Because the $10 \mathrm{~cm}$ thick upper mudmat does not contain rebar, carbonation is assumed to cause no damage to this material. Therefore the minimum diffusion distance is $10 \mathrm{~cm}$. Although presented in the context of carbonation, Equation (3.14) is also applied to diffusioncontrolled decalcification.

Column degradation is driven by carbonation fronts advancing inside the pipe column through concrete and outside the column through grout; both processes lead to accelerated steel corrosion. Carbonation occurs faster through the grout, so only the outer carbonation front is calculated. Performance Assessment analysts anticipate discretizing the columns in $2 \mathrm{ft}$ segments for flow and transport simulations; therefore, degradation times are computed for 24 inch increments that are assumed to degrade symmetrically from the top and bottom. 
For SDU 4, the top portion of saltstone and the clean grout contains roof support trusses. The joist girder system employed for the construction of the permanent roof in SDU 4 has a depth of 28 inches (Drawing C-CC-Z-0011). The top elevation of the girder is at least 296 feet, 0 inches (Drawing C-CS-Z-0002). Thus, the bottom elevation of the girder would be no less than 294 feet, 4 inches. With a top of concrete floor elevation of 271 feet (Drawing W828992) and a maximum saltstone fill height of 24 feet, 9 inches (Phifer et al. 2006, Section 4.6.2), the maximum elevation of saltstone would be 295 feet, 9 inches. Thus, the joist girders would not extend more than 1 foot, 5 inches into the saltstone. However, Performance Assessment analysts anticipate modeling the upper 3.45 feet of grout and saltstone ("Top saltstone") as influenced by carbonation-induced steel corrosion to be conservative. The remaining saltstone thickness, with the exception of the roof support columns, degrades by decalcification.

The 12 inch "FloorUMM" thickness for SDU 2 denotes the combination of an 8 inch floor with rebar and a 4 inch upper mudmat without rebar. "Grout” thicknesses include saltstone and clean grout that covers the saltstone. Decalcification of concrete by diffusion is much slower than sulfate attack and carbonation and not limiting; only bestestimate values are provided to indicate the slowness of this process. Sulfate attack and carbonation occur simultaneously, generally meeting at a point in the interior of the concrete. Thus the indicated degradation times are usually the same for both phenomena. Exceptions occur when one phenomenon is significantly delayed, such that the other mechanism is capable of degrading the entire thickness before the lag time of the former expires. Carbonation does not damage saltstone in general, an exception being in the vicinity of vertical steel columns supporting the roof. These column regions degrade differently than the surrounding grout and saltstone.

Degradation times are defined for sulfate attack, carbonation-induced steel corrosion, and decalcification in Tables 5-1 through 5-3. The difference between the CE, NV, and BE values is an indication of the level of uncertainty inherent in the underlying degradation analyses. The nominal values, which are intended to reflect moderate conservatism, are recommended for baseline Performance Assessment simulations. 
Table 5-1. Degradation analysis for SDU 2 concrete and saltstone.

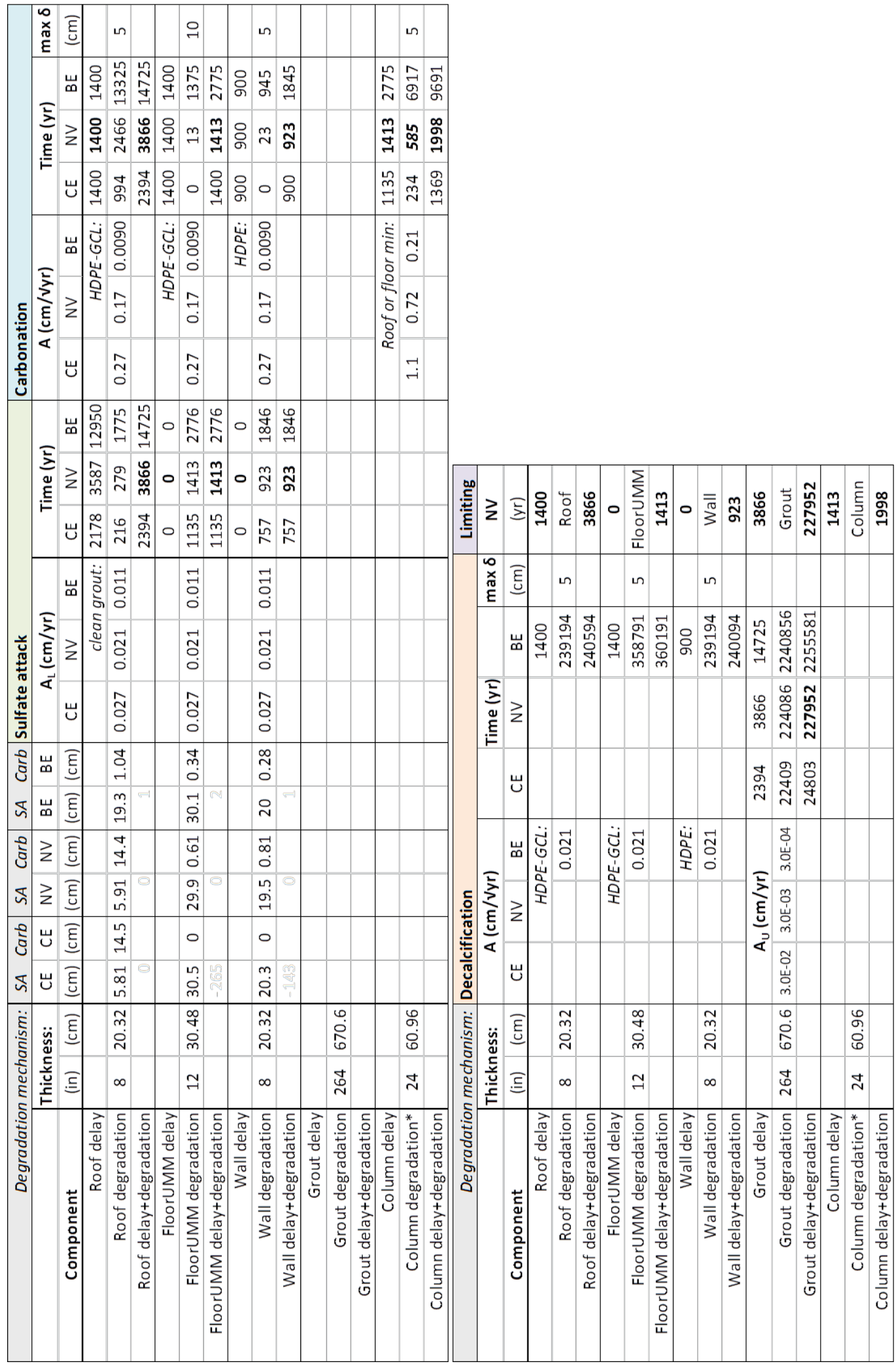

* Use degradation time for successive column segments 
Table 5-2. Degradation analysis for SDU 4 concrete and saltstone.

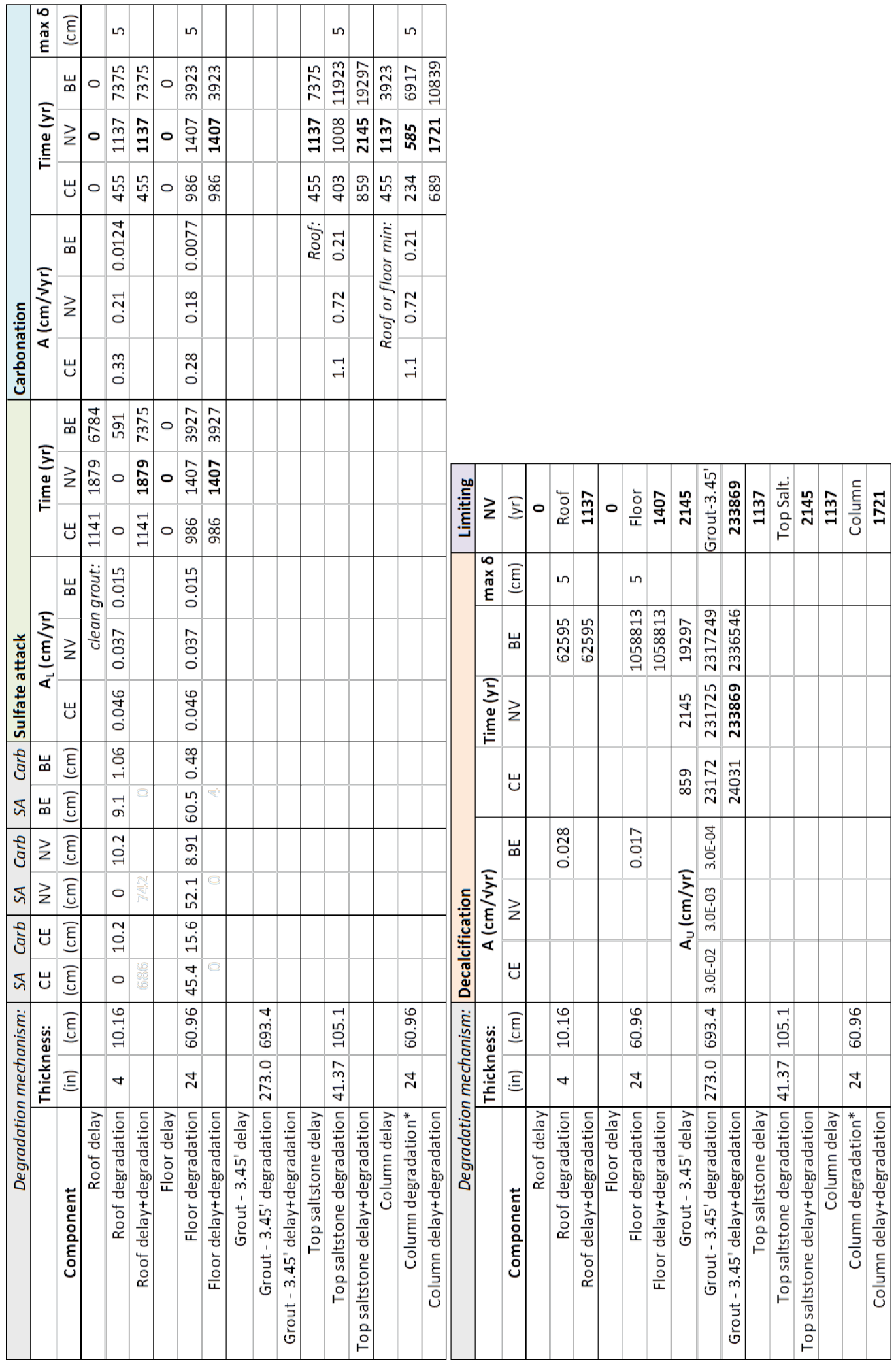

* Use degradation time for successive column segments 
Table 5-3. Degradation analysis for SDU 1 concrete and saltstone.

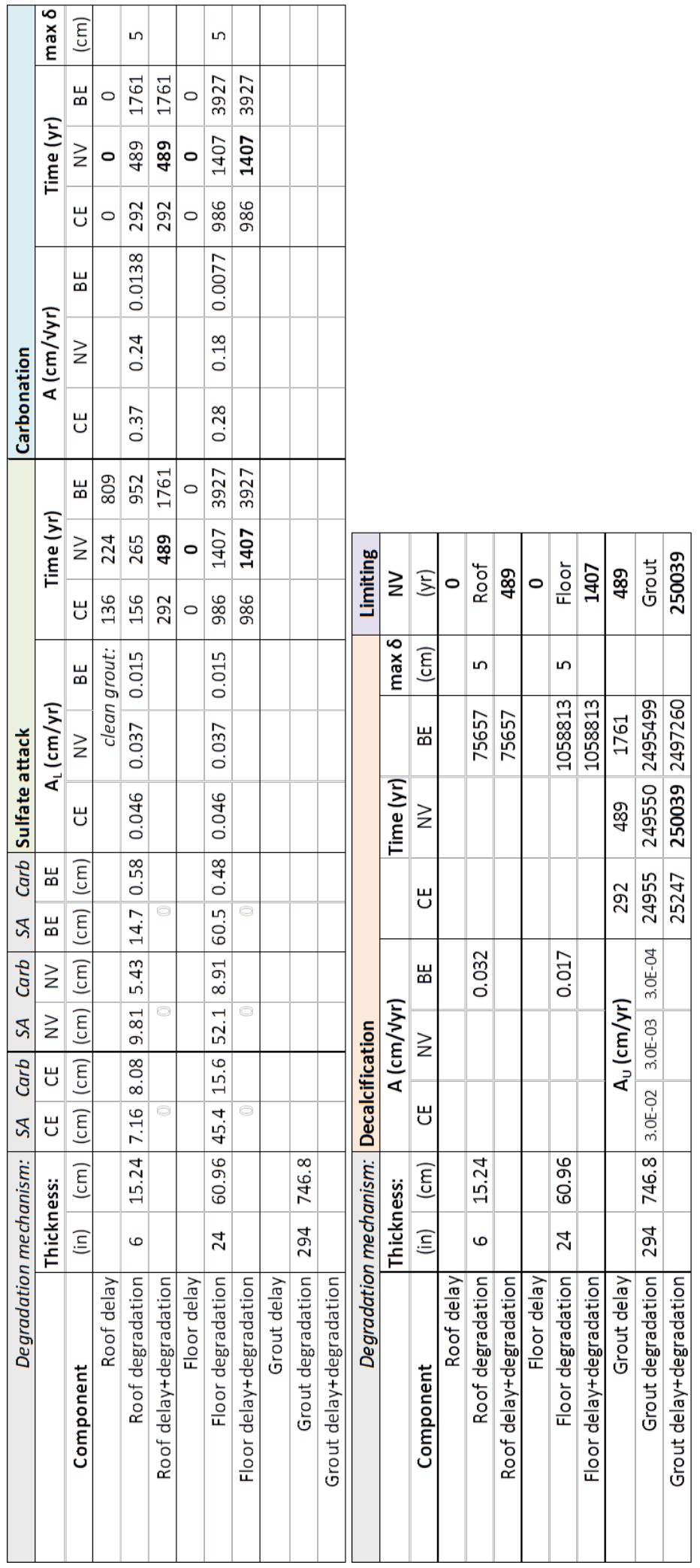


SRNL-STI-2013-00118, REVISION 0

Table 5-4. Degradation of HDPE and HDPE-GCL materials.

\begin{tabular}{|c|c|c|c|c|}
\hline \multirow{2}{*}{$\begin{array}{c}\text { Time Period } \\
\text { (years) }\end{array}$} & HDPE Hydraulic Conductivity & \multicolumn{2}{|c|}{$\begin{array}{c}\text { HDPE-GCL Hydraulic } \\
\text { Conductivity }\end{array}$} \\
\cline { 2 - 5 } & $\begin{array}{c}\text { Value } \\
\text { (cm/sec) }\end{array}$ & $\begin{array}{c}\text { Ratio to Initial } \\
\text { Value }\end{array}$ & $\begin{array}{c}\text { Value } \\
\text { (cm/sec) }\end{array}$ & $\begin{array}{c}\text { Ratio to Initial } \\
\text { Value }\end{array}$ \\
\hline $0-50$ & $5.87 \mathrm{E}-10$ & 1 & $2.19 \mathrm{E}-11$ & 1 \\
\hline $900-1,000$ & $6.04 \mathrm{E}-08$ & 103 & $1.50 \mathrm{E}-09$ & 68.5 \\
\hline $1,400-1,600$ & $9.69 \mathrm{E}-08$ & 165 & $2.31 \mathrm{E}-09$ & 105 \\
\hline $9,500-$ & & & & 498 \\
10,000 & $6.44 \mathrm{E}-07$ & 1,097 & $1.09 \mathrm{E}-08$ & 49 \\
\hline
\end{tabular}

\subsection{REFERENCES}

Bannochie, C. J., Tables Containing Results for the Fourth Quarter 2011 Tank 50 WAC Slurry Sample: Chemical and Radionuclide Contaminant Results, SRNL-L3100-201100235, December 2011.

Brown, K. G., J. Arnold, S. Sarkar, G. Flach, H. van der Sloot, J. C. L. Meeussen, and D. S. Kosson, Modeling Carbonation of High-Level Waste Tank Integrity and Closure, NUCPERF 2012 Conference, Cadarache, France, November 12-15, 2012.

Brown, K. G., F. Smith and G. Flach, GoldSim Dynamic-Link Library (DLL) Interface for Cementitious Barriers Partnership (CBP) Code Integration - 11444, WM2011 Conference, February 27 - March 3, Phoenix, AZ, 2011a.

Brown, K. G., F. Smith, G. Flach, and S. Sarkar, Cementitious Barriers Partnership (CBP) Phase I Code Integration - 11446, WM2011 Conference, February 27 - March 3, Phoenix, AZ, 2011b.

Brown, K., D. Kosson, A. Garrabrants, S. Sarkar, G. Flach, C. Langton, F. Smith, H. Burns, H. Van Der Sloot, J. Meeussen, E. Garboczi, J. Bullard, P. Stutzman, E. Samson, P. Mallick, L. Suttora, D. Esh, M. Fuhrmann, and J. Philip, Cementitious Barriers Partnership (CBP): Training and Release of CBP Toolbox Software, Version 1.0 13480, WM2013 Conference, February 24 - 28, Phoenix, AZ, $2013 a$.

Brown, K., D. Kosson, A. Garrabrants, S. Sarkar, G. Flach, C. Langton, F. Smith, H. Burns, H. Van Der Sloot, J. Meeussen, E. Garboczi, J. Bullard, P. Stutzman, E. Samson, P. Mallick, L. Suttora, D. Esh, M. Fuhrmann, and J. Philip, Cementitious Barriers Partnership (CBP): Using the CBP Software Toolbox to Simulate Sulfate Attack and Carbonation of Concrete Structures - 13481, WM2013 Conference, February 24 - 28, Phoenix, AZ, 2013b.

Clodic, L., and A. Meike, Development of a Database to Model Concrete Dissolution at $25^{\circ} \mathrm{C}$ Using the EQ3/6 Geochemical Modeling Code, Lawrence Livermore National Laboratory report UCRL-ID-132088, August 1997. 
Dean, B., Salt solution concentration estimate for Saltstone closure, SRNS-J2100-200900001, Rev. 0. January 2009.

Dixon, K., Moisture Retention Properties of High Temperature Cure ARP/MCU Saltstone Grout, SRNL-STI-2011-00661, Rev. 0, December 2011.

Flach, G. P., J. M. Jordan, and T. Whiteside, Numerical Flow and Transport Simulations Supporting the Saltstone Disposal Facility Performance Assessment, SRNL-STI-200900115, Rev. 1, June 2009.

Fredlund, D. G., and H. Rahardjo, Soils Mechanics for Unsaturated Soils, John Wiley, New York, 1993.

Hall, C. and W. Hoff, Water Transport in Brick, Stone and Concrete, Spon Press, New York, 2002.

Isom, S. T., Analysis of Saltstone Water-to-Premix Ratio During Pre-ELAWD Operation, Calculation No. X-CLC-Z-00050, October 10, 2012.

Langton, C. A., Chemical Degradation Assessment of Cementitious Materials for the HLW Tank Closure Project (U), WSRC-STI-2007-00607, Rev. 0, September 2007.

Langton, C. A., Chemical Degradation Assessment for the H-Area Tank Farm Concrete Tanks and Fill Grouts, SRNL-STI-2010-00035, Rev. 0, January 2010a.

Langton, C. A., Saltstone Characterization and Parameters for Performance Assessment Modeling; SIMCO Technologies, Inc. Task 6 Report Update; SIMCO Technologies, Inc. Subcontract SIMCORD08009 Order AC48992N (U), SRNL-STI-2010-00515, August 2010b.

Marrero, T. R., and E. A. Mason, Gaseous Diffusion Coefficients, J. Phys. Chem. Ref. Data, Vol. 1, No. 1, www.nist.gov/data/PDFfiles/jpcrd1.pdf, 1972.

Millings, M. Summary of Carbon Dioxide in Water Table Wells and the Vadose Zone at SRS, Savannah River National Laboratory memorandum SRNL-L3200-2012-00017, May 30, 2012.

Meeussen, J. C. L., H. A. van der Sloot, D. S. Kosson, and S. Sakar, Demonstration of LeachXS/Orchestra Capabilities by Simulating Constituent Releas from a Cementitious Waste Form in a Reinforced Concrete Vault, Cementitious Barriers Partnership technical report CBP-TR-2010-007-C1, Rev. 0, March 2010.

Myer, G. E., Analytical Methods in Conduction Heat Transfer, McGraw-Hill, New York, 1971.

Papadakis, V. G., C. G. Vayenas, and M. N. Fardis, A Reaction Engineering Approach to the Problem of Concrete Carbonation, AIChE Journal, 35:1639-1650. 
Phifer, M. A., M. R. Millings, and G. P. Flach, Hydraulic Property Data Package for the E-Area and Z-Area Soils, Cementitious Materials, and Waste Zones, WSRC-STI-200600198, September 2006.

Protière, Y., E. Samson, and P. Henocq, Modeling the long-term durability of concrete barriers in the context of low-activity waste storage, NUCPERF 2012 Conference, Cadarache, France, November 12-15, 2012.

Rast, R., and M. W. Rinker, Overview of Hanford Single Shell Tank (SST) Structural Integrity - 12123, WM2012 Conference, February 26 - March 1, 2012.

Reigel, M. M., B. R. Pickenheim, and W. E. Daniel, Process Formulations and Curing Conditions that Affect Saltstone Properties, SRNL-STI-2012-00558 Rev. 0, September 2012

Richards, B. G., Measurement of free energy of soil moisture by the psychrometric technique using thermistors, in Moisture Equilibria and Moisture Changes in Soils Beneath Covered Areas: A Symposium, p. 39-46, Butterworths, Australia, 1965.

Samson, E., P. Henocq, and J. Marchand, Chemical Degradation Review, Cementitious Barriers Partnership technical report CBP-TR-2009-002-C4, Rev. 0, November 2009.

Samson, E., Cementitious Barriers Partnership Task 7 Demonstration Of STADIUM® For The Performance Assessment Of Concrete Low Activity Waste Storage Structures, CBP-TR-2010-007-C3, Rev. 0, Cementitious Barriers Partnership, http://cementbarriers.org, 2010.

Sarkar, S., S. Mahadevan, J. C. L. Meeussen, H. Van Der Sloot, and D. S. Kosson, Numerical Simulation of Cementitious Materials Degradation Under External Sulfate Attack, Cement and Concrete Composites, 32:241-252, 2010a.

Sarkar, S., S. Mahadevan, J. C. L. Meeussen, H. Van Der Sloot, K. Brown, and D. S. Kosson, Probabilistic Durability Analysis Of Cementitious Materials Under Combined Sulfate Attack And Calcium Leaching - 10149, WM2010 Conference, March 7 - 11, Phoenix, AZ, 2010b.

Sarkar, S., D. S. Kosson, S. Mahadevan, H. Meeussen, H. Van Der Sloot, K. G. Brown, G. Flach, and C. Langton, Effects of Various Factors on Durability Prediction of Nuclear Waste Containment Structures - 11546, WM2011 Conference, February 27 - March 3, Phoenix, AZ, 2011.

Seol, Y., H. H. Liu, and G. S. Bodvarsson, Effects of dry fractures on matrix diffusion in unsaturated fractured rocks, Geophysical Research Letters, vol. 30, no. 2, 1075, doi:10.1029/2002GL016118, 2003.

SIMCO, Washington Savannah River Company Subcontract AC81850N Report - Vault Concrete Characterization, SIMCO Technologies Inc., Quebec Canada, March 2012. 
SIMCO, Washington Savannah River Company Subcontract no. AC48992N Report; Task 6 - Characterization of a Wasteform Mixture, SIMCO Technologies Inc., Quebec Canada, June 2010.

SRR Closure \& Waste Disposal Authority, Performance Assessment for the Saltstone Disposal Facility at the Savannah River Site, SRR-CWDA-2009-00017, Rev. 0, October 2009.

van Genuchten, M. T., A closed-form equation for predicting the hydraulic conductivity of unsaturated soils, Soil Science Society America Journal, vol. 44, no. 5, pp. 892-898, 1980.

Walton, J. C., L. E. Plansky, and R. W. Smith, Models for Estimation of Service Life of Concrete Barriers in Low-Level Radioactive Waste Disposal, NUREG/CR-5542, September 1990.

Wang, J. S. Y., and T. N. Narasimhan, Hydrologic Mechanisms Governing Fluid Flow in a Partially Saturated, Fractured, Porous Medium, Water Resources Research, vol. 21, no. 12, pp. 1861-1874, 1985. 


\section{Distribution:}

R. S. Aylward, 773-42A

H. H. Burns, 773-41A

B. T. Butcher, 773-43A

T. W. Coffield, 705-1C

D. A. Crowley, 773-43A

W. B. Dean, 705-1C

G. P. Flach, 773-42A

M. B. Gorensek, 703-41A

J. C. Griffin, 773-A

M. K. Harris, 703-41A

J. M. Jordan, 703-41A

C. A. Langton, 773-43A

J. E. Laurinat, 703-41A

B. H. Lester, 705-1C

S. L. Marra, 773-A

M. A. Phifer, 773-42A

K. H. Rosenberger, 705-1C

R. R. Seitz, 773-43A

R. E. Sheppard, 705-1C

F. G. Smith, III 703-41A

G. A. Taylor, 773-43A

C. Wilson (1 file copy \& 1 electronic copy), 773-43A - Rm.213 